\title{
Evaluating Electron Transfer Reactivity of Rare-Earth Metal(II) Complexes Using EPR
}

\section{Spectroscopy}

\author{
Samuel A. Moehring, William J. Evans* \\ Department of Chemistry, University of California, Irvine, California 92697-2025, United States \\ Email:wevans@uci.edu
}

*To whom correspondence should be addressed. 
Table of Contents

$\begin{array}{ll}\text { Experimental } & \text { S3 }\end{array}$

EPR Spectra of $\left[\mathrm{Ln}^{\mathrm{II}} \mathrm{Cp}^{\prime}{ }_{3}\right]^{1-}$ Reactions with $\mathrm{Cp}^{\prime}{ }_{3} \mathrm{Ln}^{\prime \text { III }}$ Complexes $\quad$ S4-S11

EPR Spectra of $\left[\mathrm{Ln}^{\mathrm{II}}\left(\mathrm{NR}_{2}\right)_{3}\right]^{1-}$ Reactions with $\mathrm{Ln}^{\prime \text { III }}\left(\mathrm{NR}_{2}\right)_{3}$ Complexes $\quad$ S12-S14

EPR Spectra of $\left[\mathrm{Ln}^{\mathrm{II}} \mathrm{A}_{3}\right]^{1-}$ Reactions with $\mathrm{Ln}^{\mathrm{III}} \mathbf{A}^{\prime}{ }_{3}$ Complexes $\quad$ S15-S22

$$
\begin{array}{lr}
\text { Ln }=\text { Y } & \text { S15-S17 } \\
\text { Ln }=\text { Sc } & \text { S18 } \\
\text { Ln }=\text { La } & \text { S19-S21 }
\end{array}
$$

EPR and NMR Spectra of $\left[\mathrm{La}^{\mathrm{II}} \mathrm{Cp}^{\prime \prime}{ }_{3}\right]^{1-}+\mathrm{KA}:$ Ligand Exchange Reactions $\quad$ S22-S25

EPR Evidence for Reduced 2.2.2-cryptand in THF Acting as a Reductant $\quad$ S26

$\begin{array}{ll}\text { References } & \text { S27 }\end{array}$ 


\section{EXPERIMENTAL}

All manipulations and syntheses were conducted with the rigorous exclusion of air and water using standard Schlenk line and glovebox techniques under an argon atmosphere. Solvents were sparged with UHP argon and dried by passage through columns containing Q-5 and molecular sieves prior to use. Deuterated NMR solvents were dried over NaK alloy or $\mathrm{Na} /$ benzophenone, degassed by three freeze-pump-thaw cycles, and vacuum transferred before use. ${ }^{1} \mathrm{H}$ NMR spectra were recorded on a Bruker AVANCE600 spectrometer $\left({ }^{1} \mathrm{H}\right.$ operating at $\left.600 \mathrm{MHz}\right)$ at $298 \mathrm{~K}$ unless otherwise stated and referenced internally to residual protio-solvent resonances. EPR spectra were collected using X-band frequency $(9.3-9.8 \mathrm{GHz})$ on a Bruker EMX spectrometer equipped with an ER4119HS-W1 microwave bridge and the magnetic field was calibrated with DPPH $(g=$ 2.0036). In the initial report of $[\mathrm{K}(\mathrm{crypt})]\left[\mathrm{La}^{\mathrm{II}} \mathrm{Cp}_{3}{ }_{3}\right]$, the EPR spectroscopic parameters are reported to be $\mathrm{g}=1.990$ and $A\left({ }^{139} \mathrm{La}\right)=133.5 \mathrm{G} .{ }^{1}$ In all simulations in this work, reactions where $\left[\mathrm{La}^{\mathrm{II}} \mathrm{Cp}_{3}\right]^{1-}$ is present (either as a reactant or product), it is best modeled as having $\mathrm{g}=1.96$ and $A\left({ }^{139} \mathrm{La}\right)=133.5 \mathrm{G}$. All EPR parameters are taken from simulations of the room-temperature spectra using EasySpin. ${ }^{2}$ 


\section{$\left[\operatorname{Ln}^{\mathrm{II}} \mathrm{Cp}^{\prime}{ }^{3}\right]^{1-}$ Reactions with $\mathrm{Cp}^{\prime}{ }_{3} \operatorname{Ln}^{\prime \text { III }}$ Complexes}
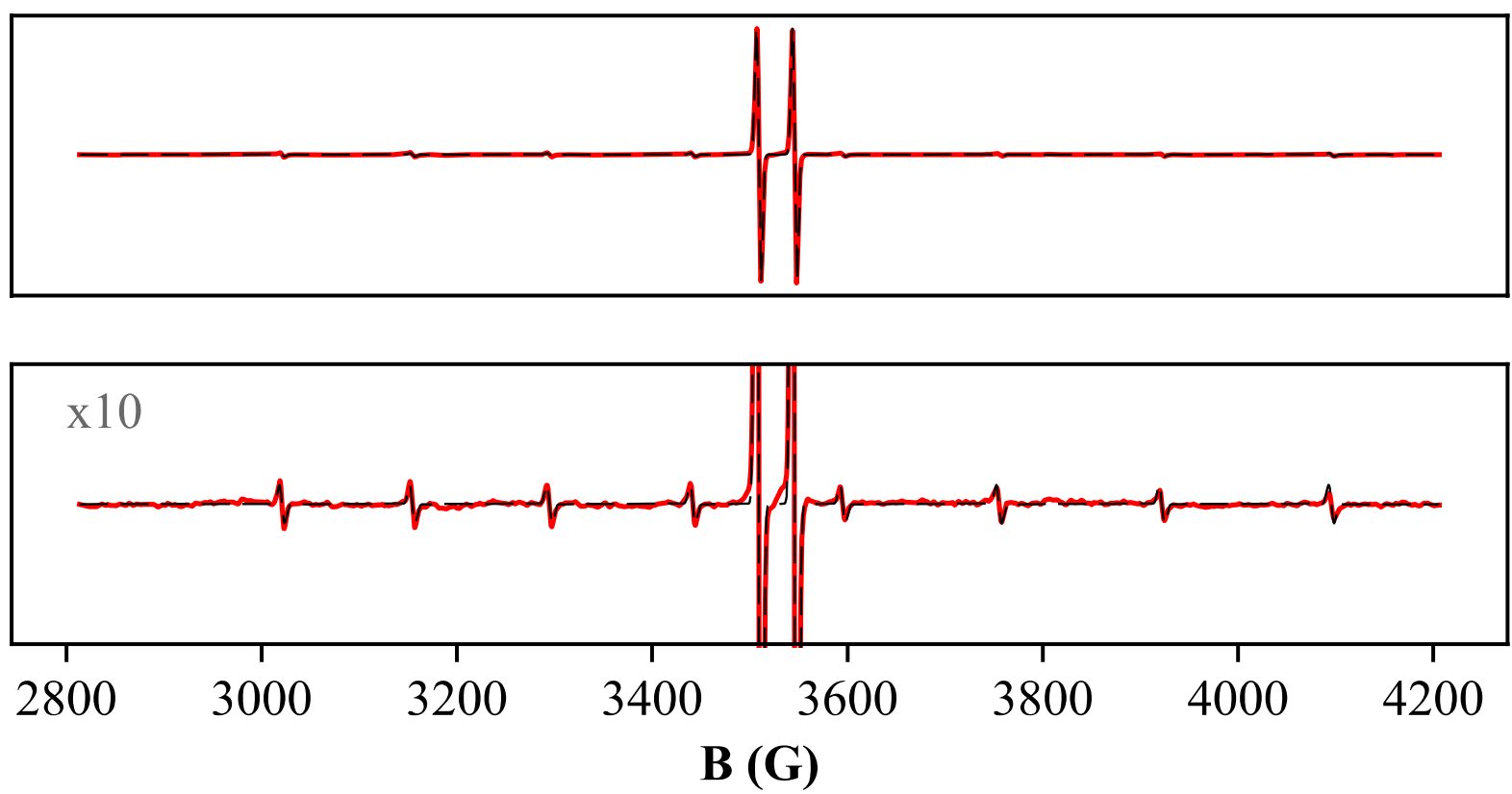

Figure S1. Room-temperature X-band EPR spectrum (red) and simulated spectrum (black dashes) of the products of reaction 2 in the forward direction, spectrum at $1 \mathrm{x}$ above and 10x below. Signals are present at $g=1.99, A\left({ }^{89} \mathrm{Y}\right)=37.1 \mathrm{G}\left(\left[\mathrm{Y}^{\mathrm{II}} \mathrm{Cp}^{\prime}{ }_{3}\right]^{1-}\right)$ and $g=1.97, A\left({ }^{139} \mathrm{La}\right)=153.4 \mathrm{G}\left(\left[\mathrm{La}^{\mathrm{II}} \mathrm{Cp}^{\prime}\right]^{1-}\right)$.
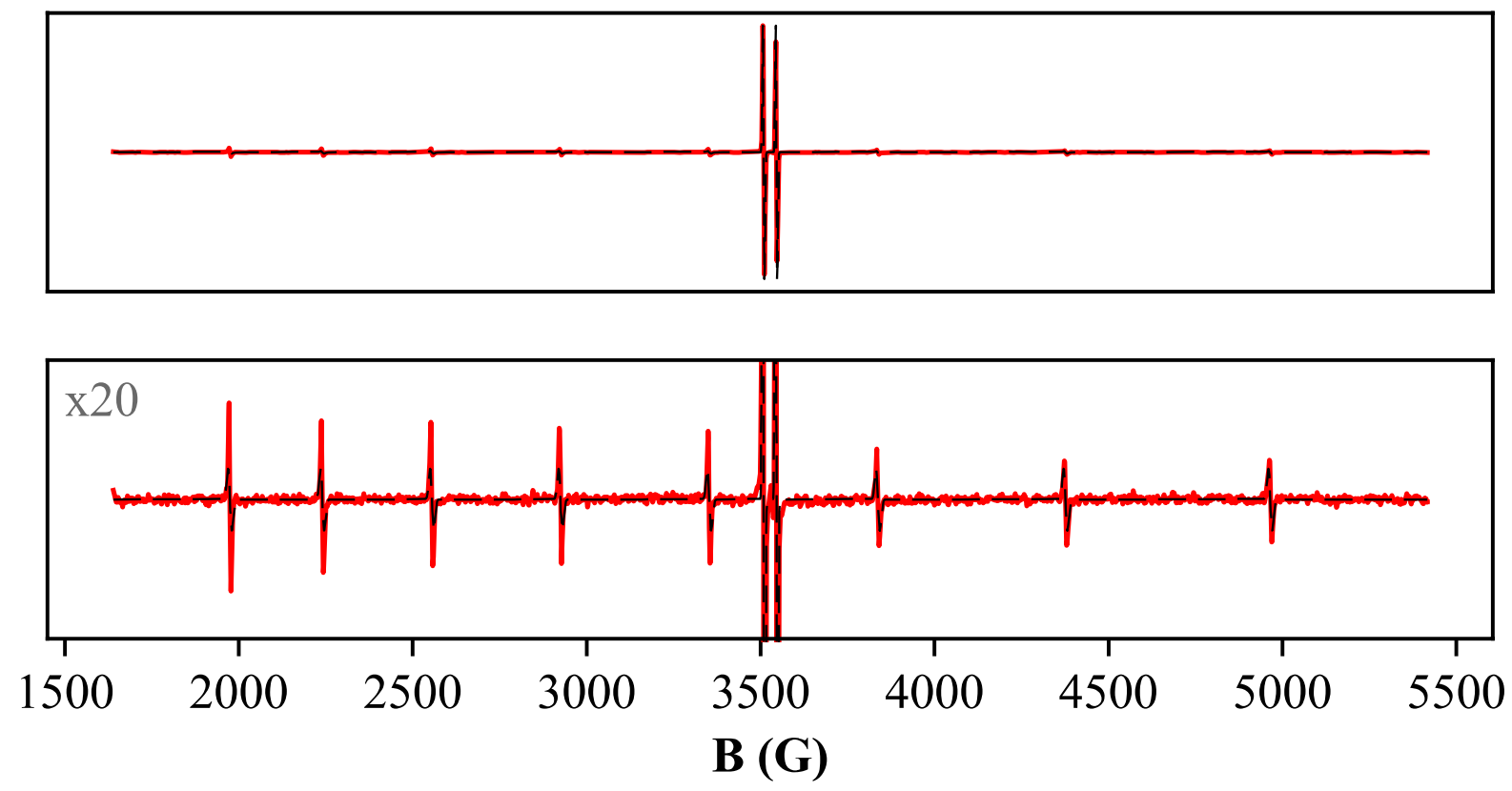

Figure S2. Room-temperature X-band EPR spectrum (red) and simulated spectrum (black dashes) of the products of reaction 3 in the reverse direction, spectrum at $1 \mathrm{x}$ above and 20x below. Signals are present at $g=1.99, A\left({ }^{89} \mathrm{Y}\right)=36.8 \mathrm{G}\left(\left[\mathrm{Y}^{\mathrm{II}} \mathrm{Cp}_{3}^{\prime}\right]^{1-}\right)$ and $g=1.97, A\left({ }^{175} \mathrm{Lu}\right)=425.7 \mathrm{G}\left(\left[\mathrm{Lu}^{\mathrm{II}} \mathrm{Cp}^{\prime}\right]^{1-}\right)^{1-}$. 


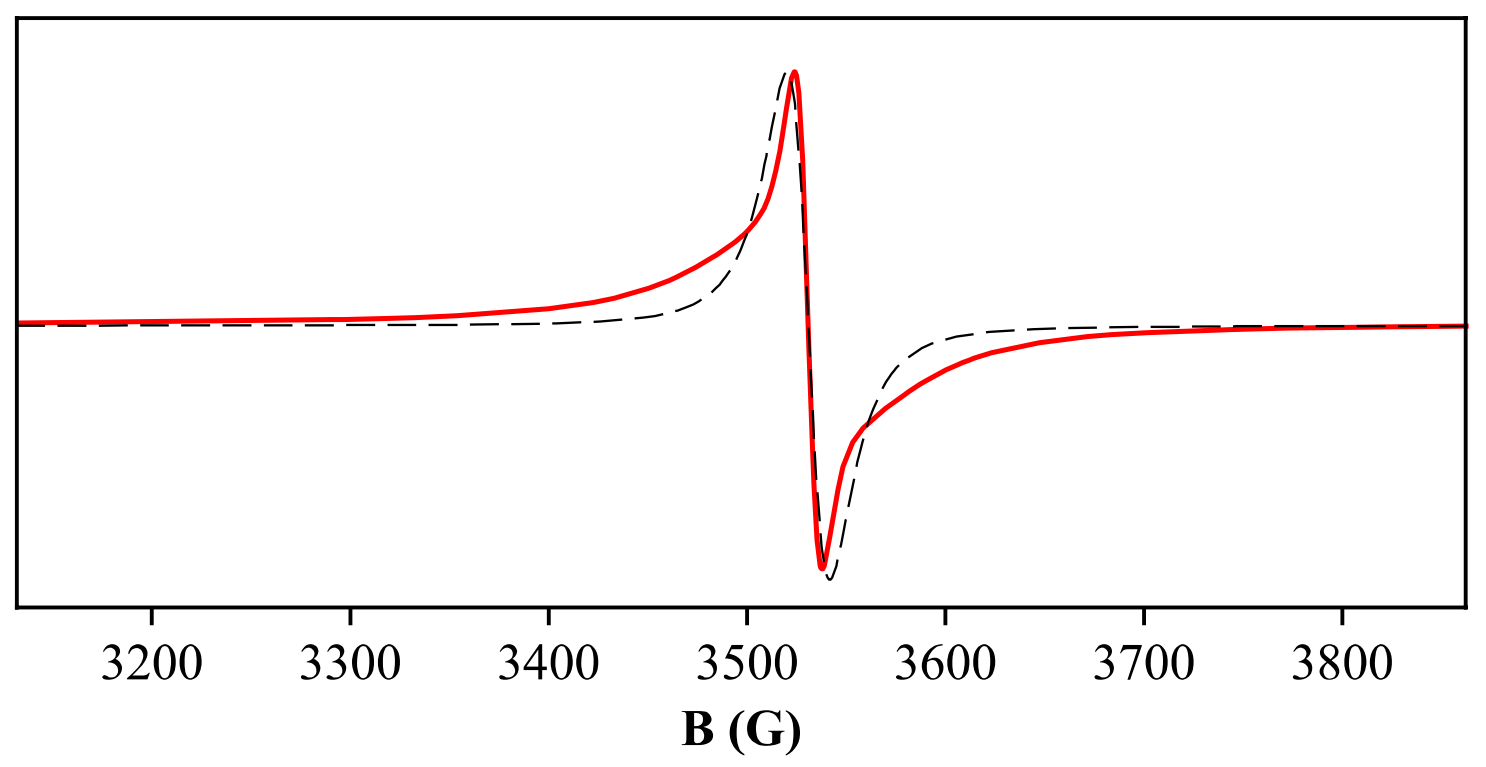

Figure S3. Room-temperature X-band EPR spectrum (red) and simulated spectrum (black dashes) of the products of reaction 5. Signal is present at $g=1.99\left(\left[\mathrm{Gd}^{\mathrm{II}} \mathrm{Cp}_{3}^{\prime}\right]^{1-}\right)$.

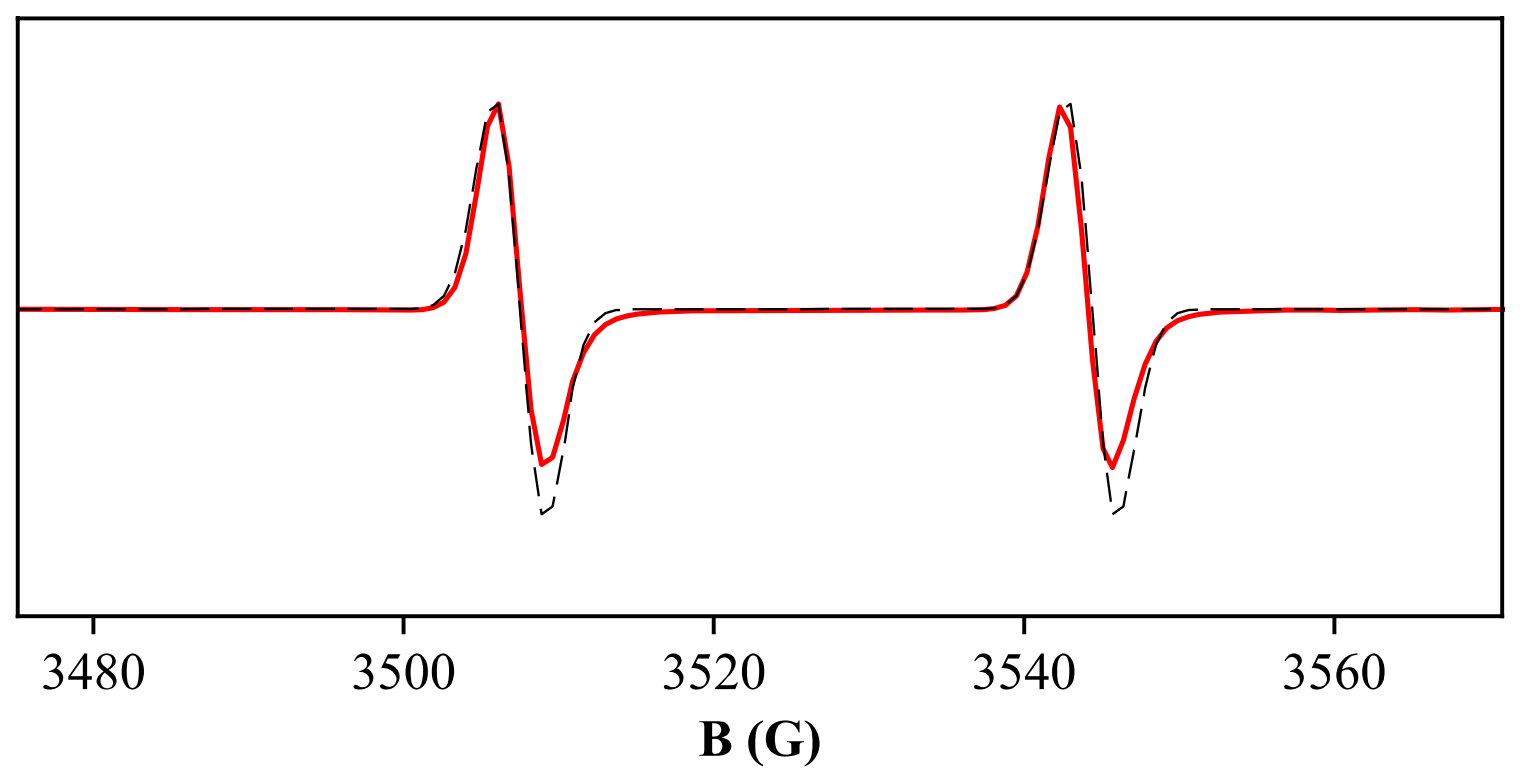

Figure S4. Room-temperature X-band EPR spectrum (red) and simulated spectrum (black dashes) of the products of reaction 2 in the reverse direction. Signal is present at $g=1.99, A\left({ }^{89} \mathrm{Y}\right)=37.3$ $\mathrm{G}\left(\left[\mathrm{Y}^{\mathrm{II}} \mathrm{Cp}^{\prime}{ }_{3}\right]^{1-}\right)$. 

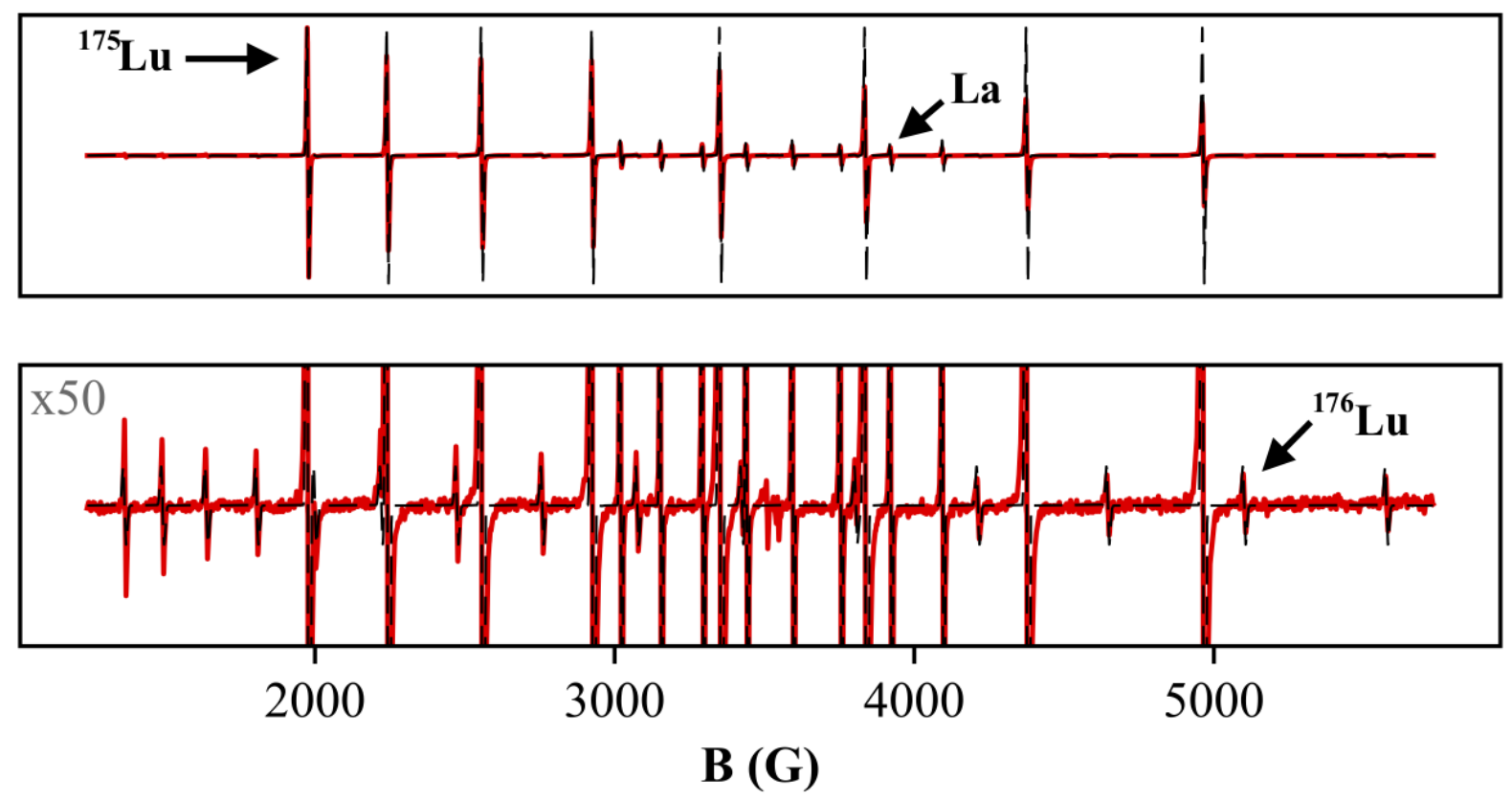

Figure S5. Room-temperature X-band EPR spectrum (red) and simulated spectrum (black dashes) of the products of reaction 4 in the reverse direction, spectrum at $1 \mathrm{x}$ above and 50x below. Signals are present at $g=1.97, A\left({ }^{139} \mathrm{La}\right)=153.5 \mathrm{G}\left(\left[\mathrm{La}^{\mathrm{II}} \mathrm{Cp}_{3}^{\prime}\right]^{1-}\right)$ and $g=1.97, A\left({ }^{175} \mathrm{Lu}\right)=425.3 \mathrm{G}$ $\left(\left[{ }^{175} \mathrm{Lu}^{\mathrm{II}} \mathrm{Cp}_{3}^{\prime}\right]^{1-}\right)$, and $g=1.97, A\left({ }^{176} \mathrm{Lu}\right)=300.3 \mathrm{G}\left(\left[{ }^{176} \mathrm{Lu}^{\mathrm{II}} \mathrm{Cp}^{\prime}{ }_{3}\right]^{1-}\right)$. The large Lu hyperfine coupling which is not first order has been discussed previously. ${ }^{3}$

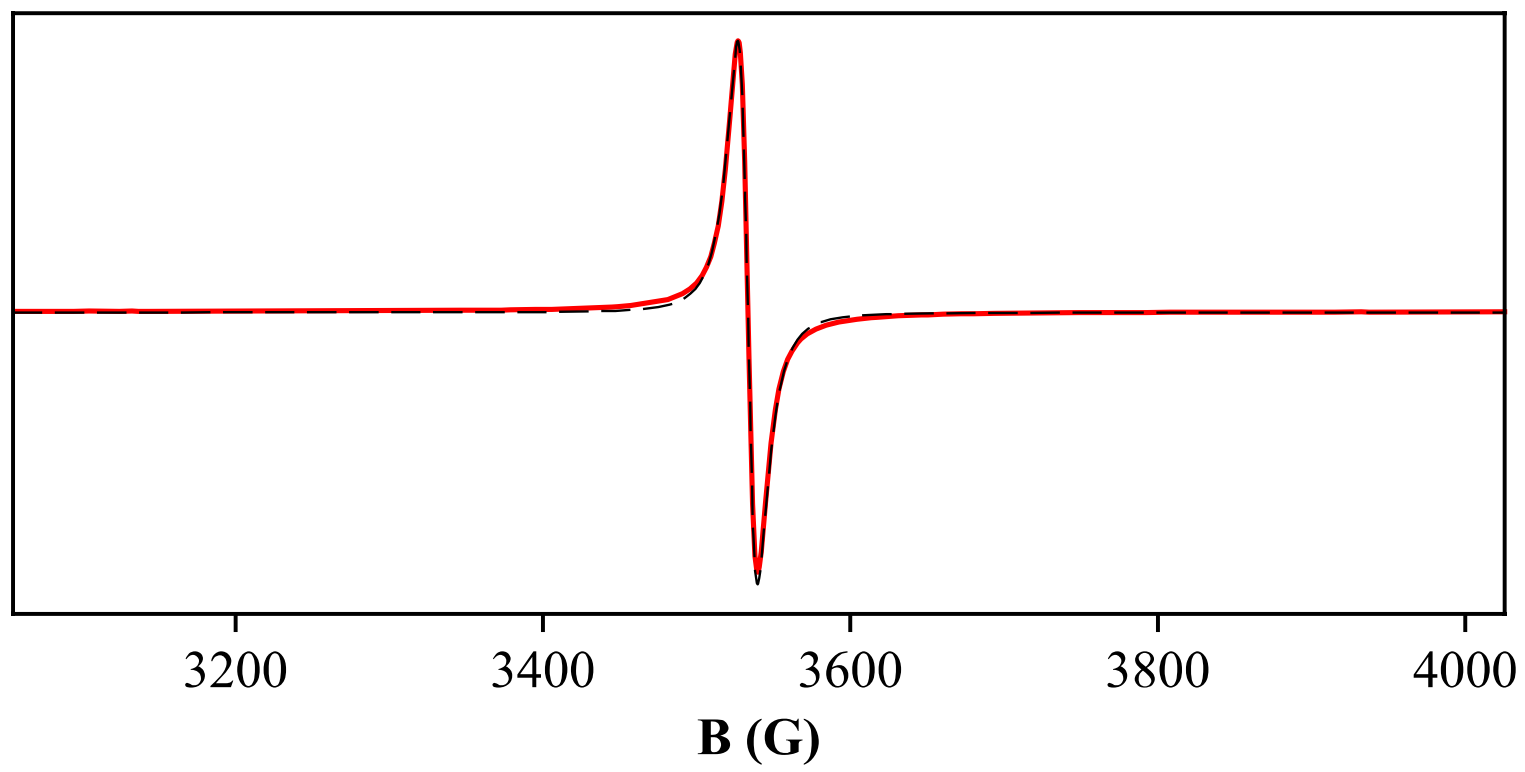

Figure S6. Room-temperature X-band EPR spectrum (red) and simulated spectrum (black dashes) of the products of reaction 6 . Signal is present at $g=1.99\left(\left[\mathrm{Gd}^{\mathrm{II}} \mathrm{Cp}^{\prime}{ }_{3}\right]^{1-}\right)$. 


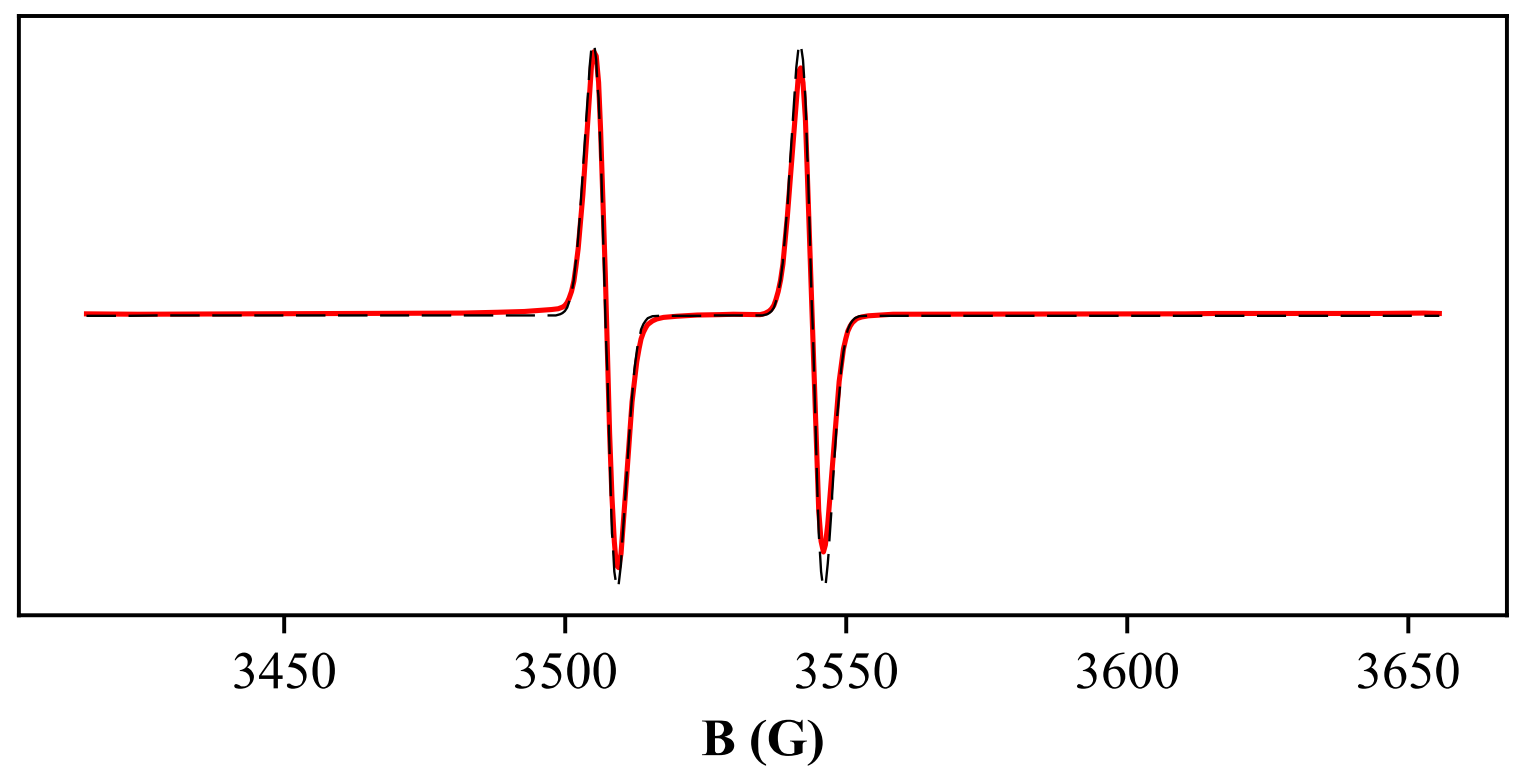

Figure S7. Room-temperature X-band EPR spectrum (red) and simulated spectrum (black dashes) of the products of reaction 3 in the forward direction. Signal is present at $g=1.99, A\left({ }^{89} \mathrm{Y}\right)=37.1$ $\mathrm{G}\left(\left[\mathrm{Y}^{\mathrm{II}} \mathrm{Cp}^{\prime}{ }_{3}\right]^{1-}\right)$.
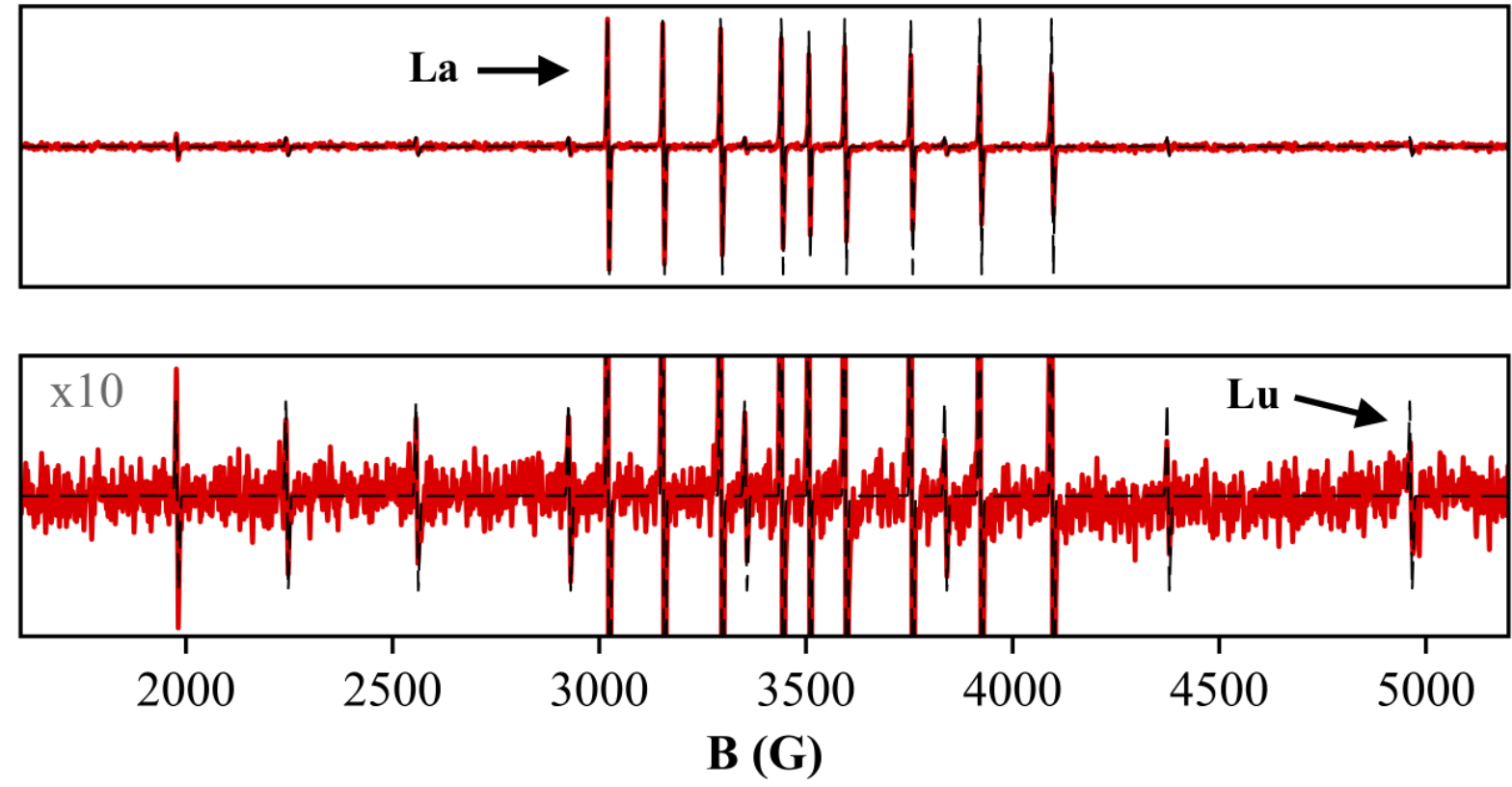

Figure S8. Room-temperature X-band EPR spectrum (red) and simulated spectrum (black dashes) of the products of reaction 4 in the forward direction, spectrum at 1x above and 10x below. Signals are present at $g=1.97, A\left({ }^{139} \mathrm{La}\right)=153.5 \mathrm{G}\left(\left[\mathrm{La}^{\mathrm{II}} \mathrm{Cp}^{\prime}\right]^{1-}\right)$ and $g=1.97, A\left({ }^{175} \mathrm{Lu}\right)=425.0 \mathrm{G}$ $\left(\left[\mathrm{Lu}^{\mathrm{II}} \mathrm{Cp}^{\prime}{ }_{3}\right]^{1-}\right)$. 


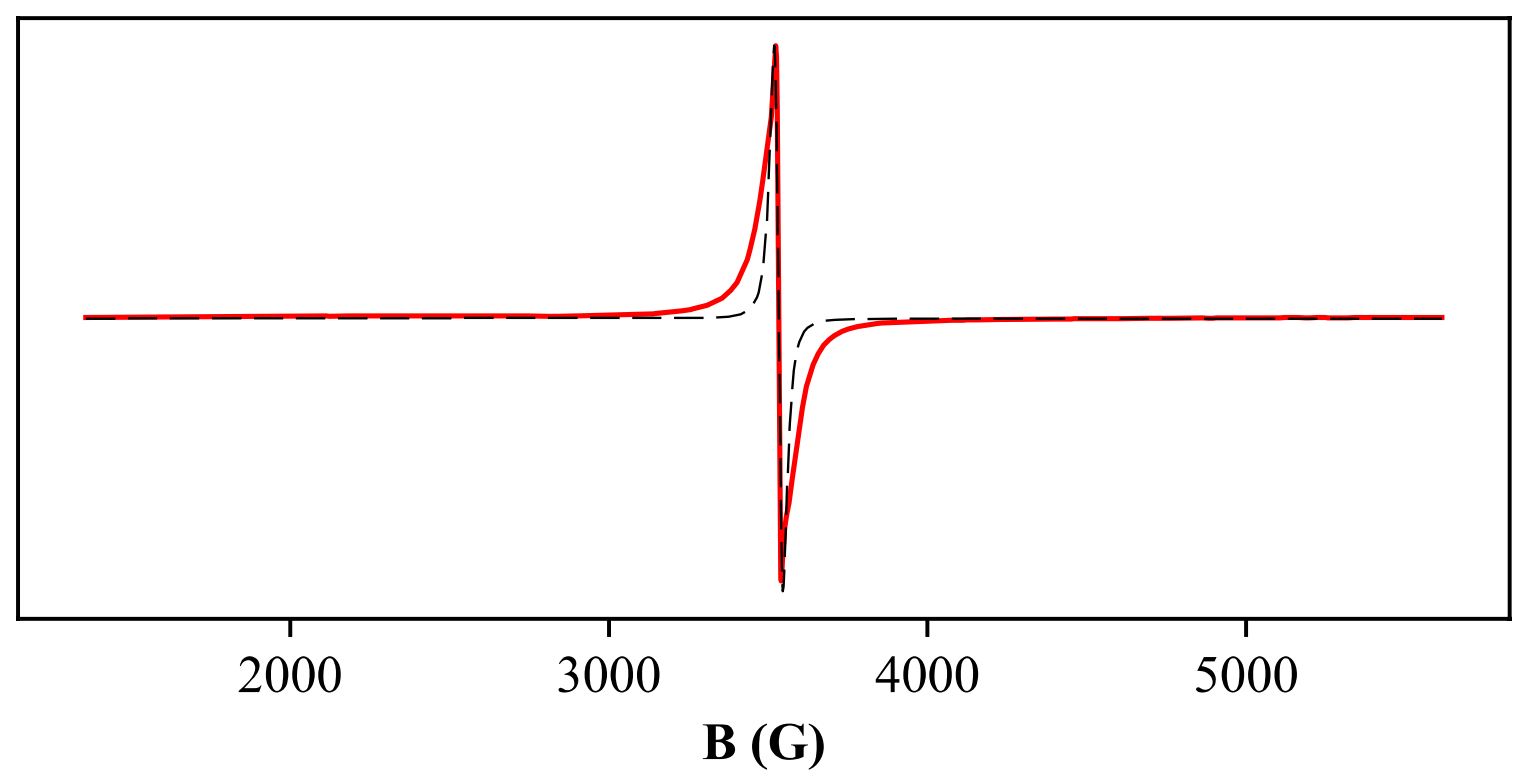

Figure S9. Room-temperature X-band EPR spectrum (red) and simulated spectrum (black dashes) of the products of reaction 7 . Signal is present at $g=1.99\left(\left[\mathrm{Gd}^{\mathrm{II}} \mathrm{Cp}_{3}^{\prime}\right]^{1-}\right)$.

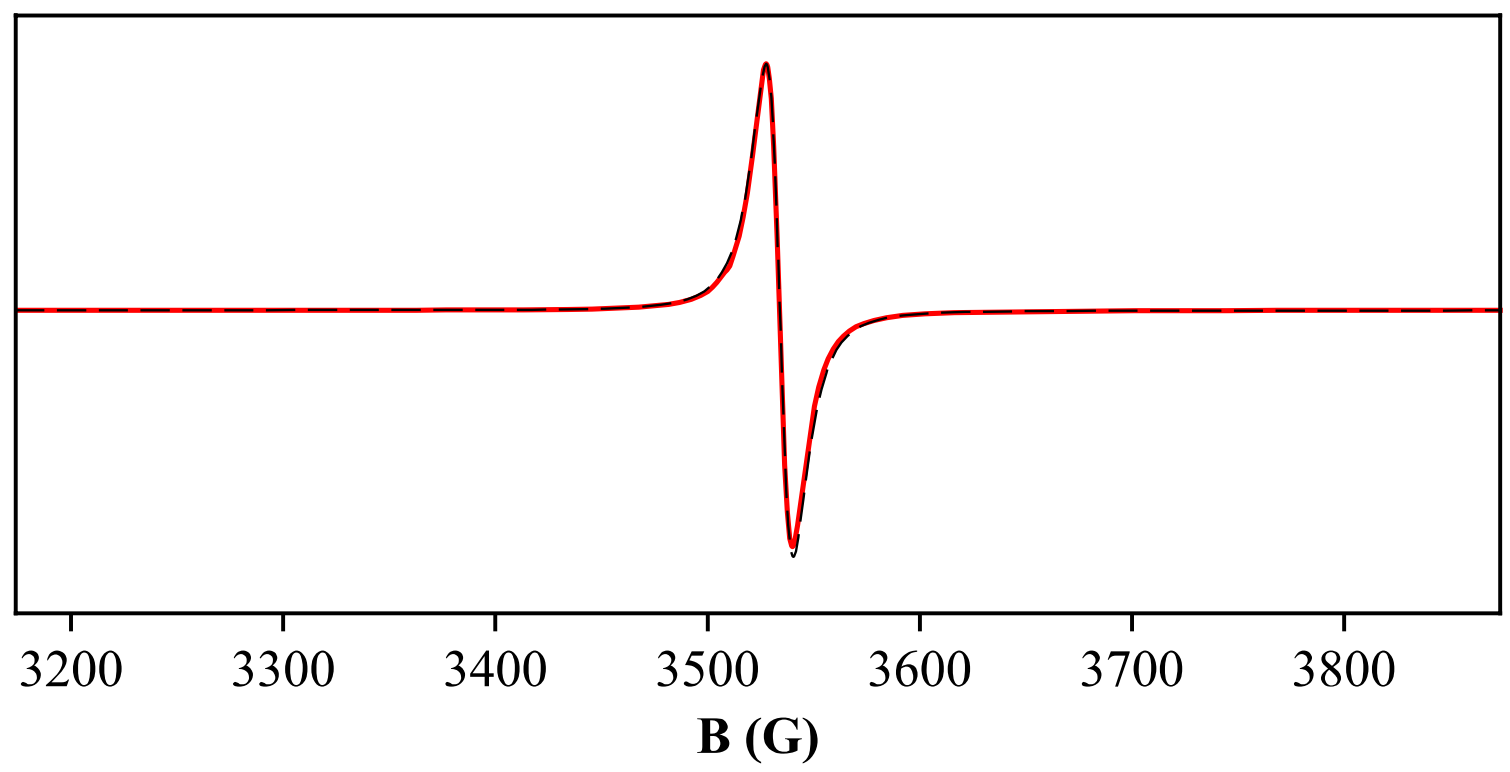

Figure S10. Room-temperature X-band EPR spectrum (red) and simulated spectrum (black dashes) of the products of reaction of $\left[\mathrm{Gd}^{\mathrm{II}} \mathrm{Cp}^{\prime}{ }_{3}\right]^{1-}$ with $\mathrm{Y}^{\mathrm{III}} \mathrm{Cp}^{\prime}{ }_{3}$. Signal is present at $g=1.99$ $\left(\left[\mathrm{Gd}^{\mathrm{II}} \mathrm{Cp}_{3}^{\prime}\right]^{1-}\right)$. 


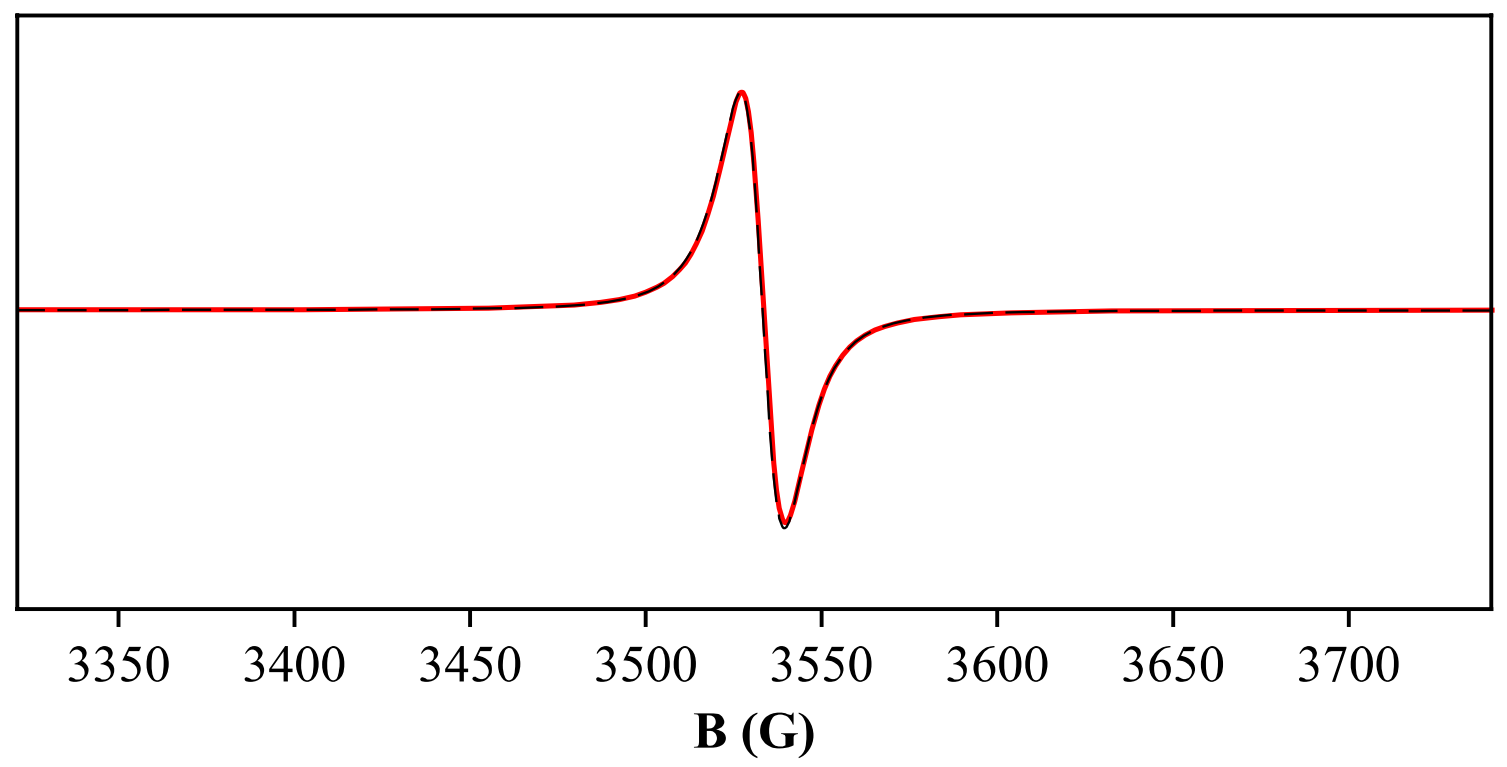

Figure S11. Room-temperature X-band EPR spectrum (red) and simulated spectrum (black dashes) of the products of reaction of $\left[\mathrm{Gd}^{\mathrm{II}} \mathrm{Cp}^{\prime}{ }_{3}\right]^{1-}$ with $\mathrm{La}^{\mathrm{III}} \mathrm{Cp}^{\prime}{ }_{3}(\mathrm{THF})$. Signals are present at $g=$ $1.99\left(\left[\mathrm{Gd}^{\mathrm{II}} \mathrm{Cp}_{3}^{\prime}\right]^{1-}\right)$.

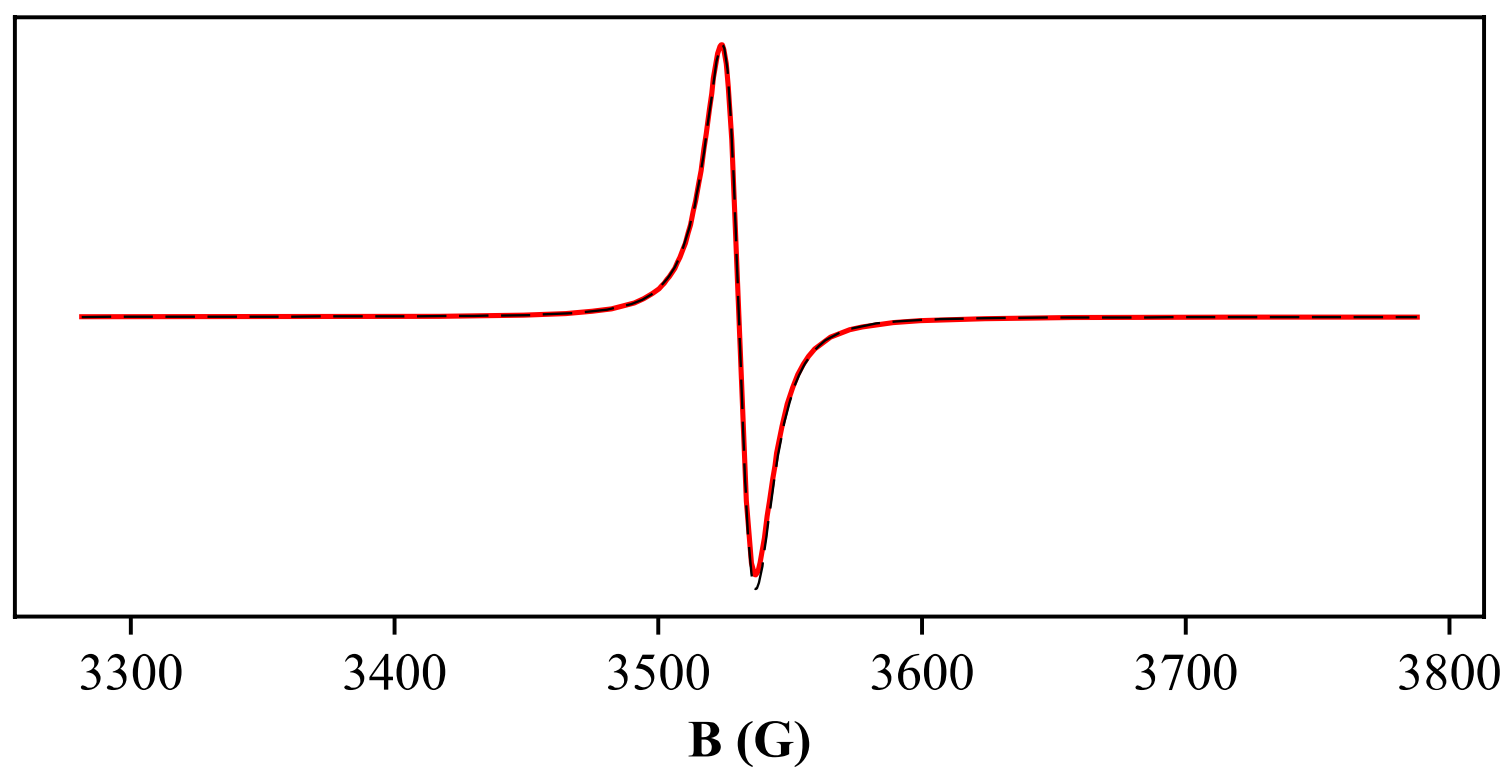

Figure S12. Room-temperature X-band EPR spectrum (red) and simulated spectrum (black dashes) of the products of reaction of $\left[\mathrm{Gd}^{\mathrm{II}} \mathrm{Cp}_{3}^{\prime}\right]^{1-}$ with $\mathrm{Lu}^{\mathrm{III}} \mathrm{Cp}^{\prime}{ }_{3}$. Signals are present at $g=1.99$ $\left(\left[\mathrm{Gd}^{\mathrm{II}} \mathrm{Cp}_{3}^{\prime}\right]^{1-}\right)$. 


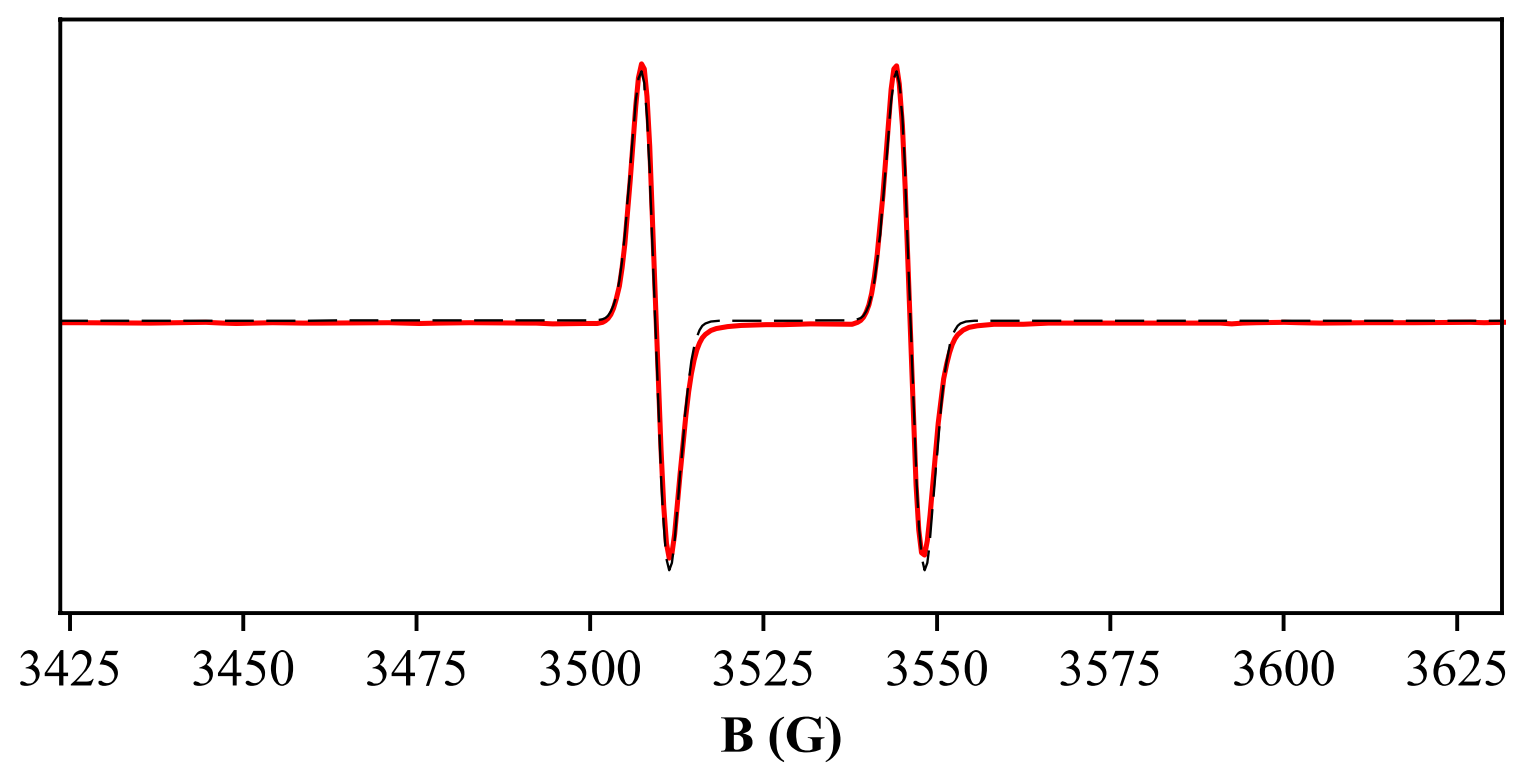

Figure S13. Room-temperature X-band EPR spectrum (red) and simulated spectrum (black dashes) of the products of reaction 8 . Signal is present at $g=1.99, A\left({ }^{89} \mathrm{Y}\right)=36.7 \mathrm{G}\left(\left[\mathrm{Y}^{\mathrm{II}} \mathrm{Cp}^{\prime}{ }_{3}\right]^{1-}\right)$.

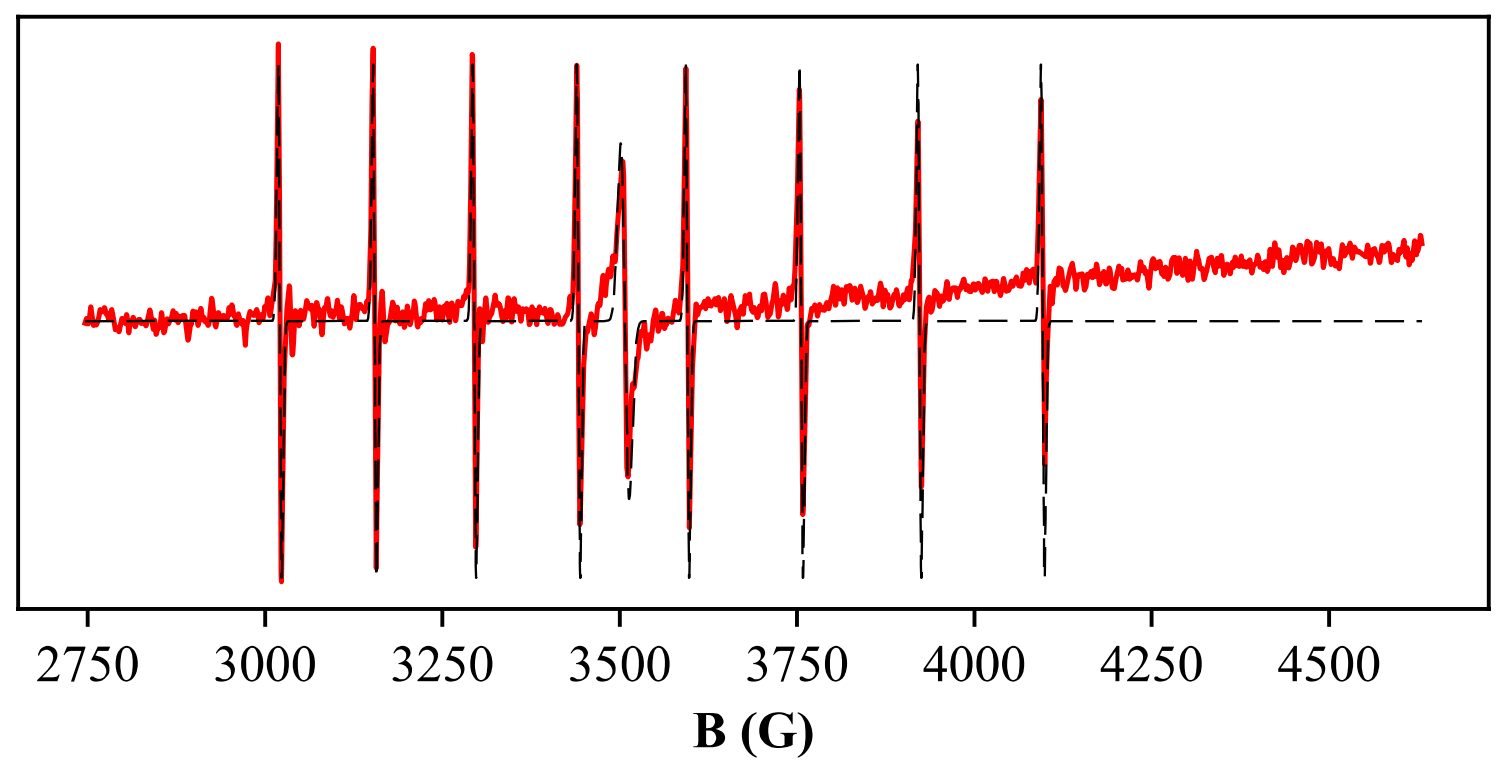

Figure S14. Room-temperature X-band EPR spectrum (red) and simulated spectrum (black dashes) of the products of reaction 9. Signals are present at $g=1.97, A\left({ }^{139} \mathrm{La}\right)=153.5 \mathrm{G}$ $\left(\left[\mathrm{La}^{\mathrm{II}} \mathrm{Cp}_{3}^{\prime}\right]^{1-}\right.$ ) and $g=2.00$ (an unknown species, likely electride). 


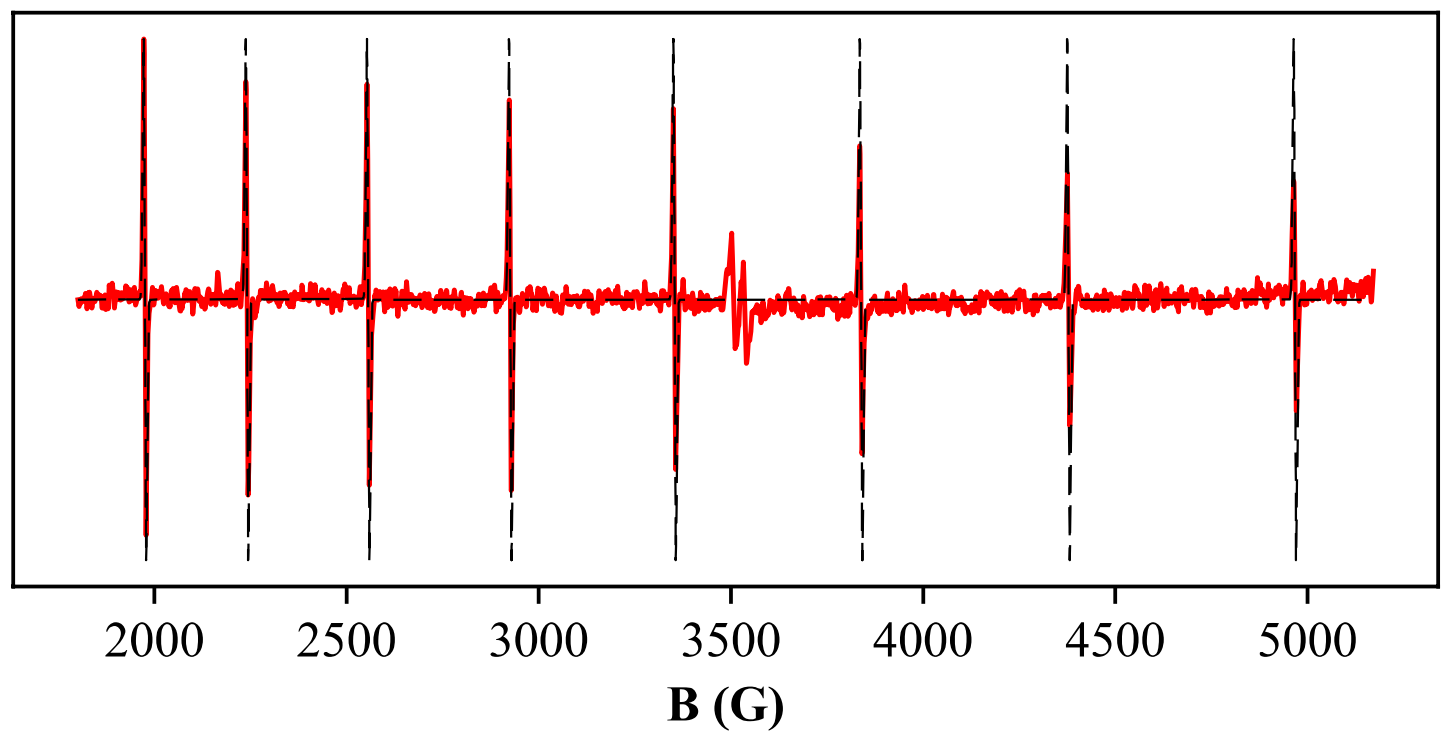

Figure S15. Room-temperature X-band EPR spectrum (red) and simulated spectrum (black dashes) of the products of reaction 10. Signals are present at $g=1.97, A\left({ }^{175} \mathrm{Lu}\right)=425.9 \mathrm{G}$ $\left(\left[\mathrm{Lu}^{\mathrm{II}} \mathrm{Cp}_{3}^{\prime}\right]^{1-}\right.$ ) and $\sim 3500 \mathrm{G}$ (an unknown species).

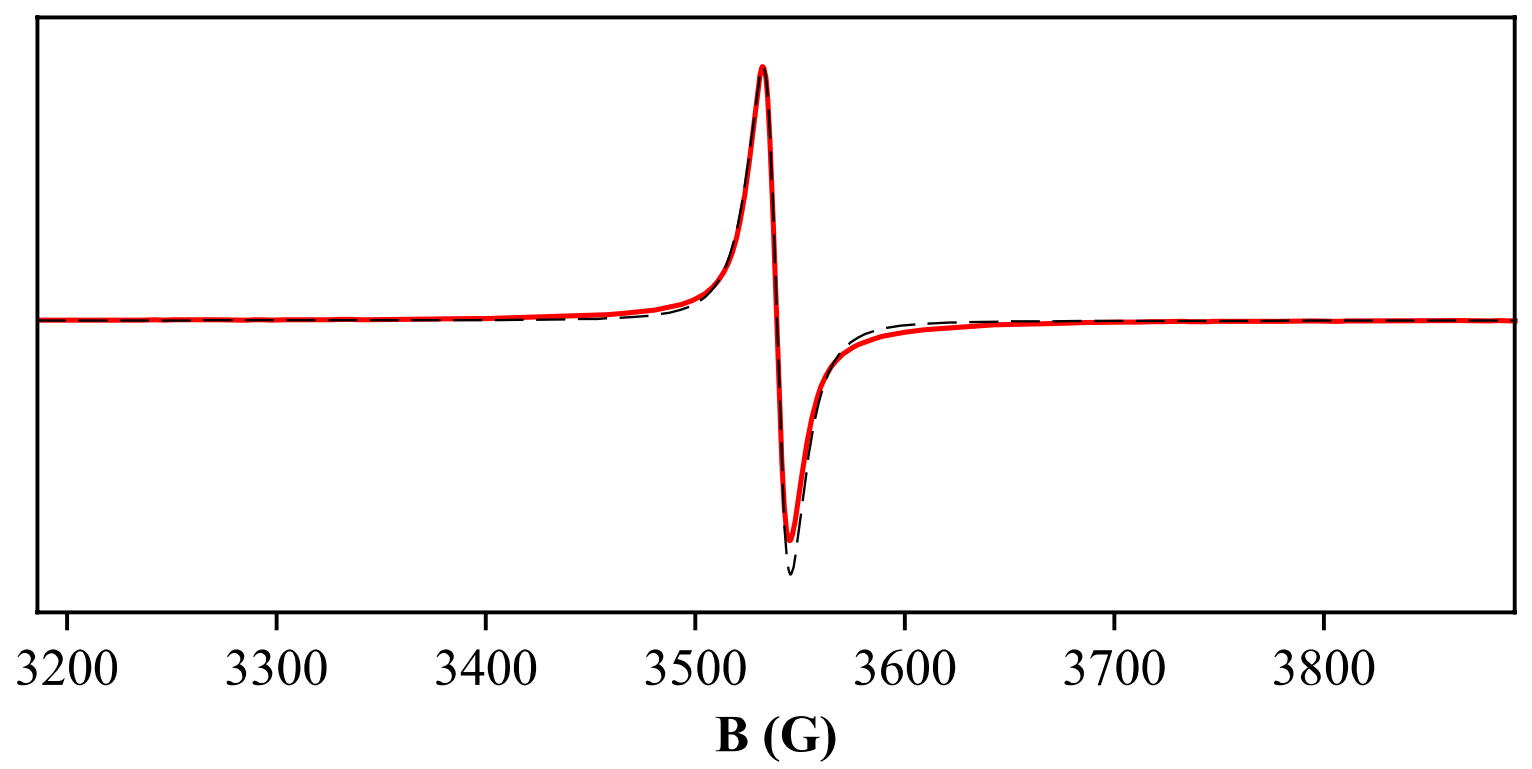

Figure S16. Room-temperature X-band EPR spectrum (red) and simulated spectrum (black dashes) of the products of reaction 11. Signal is present at $g=1.98\left(\left[\mathrm{Gd}^{\mathrm{II}} \mathrm{Cp}_{3}^{\prime}\right]^{1-}\right)$. 


\section{$\left[\operatorname{Ln}^{\mathrm{II}}\left(\mathbf{N R}_{2}\right)_{3}\right]^{1-}$ Reactions with $\mathrm{Ln}^{\prime \text { III }}\left(\mathbf{N R}_{2}\right)_{3}$ Complexes}

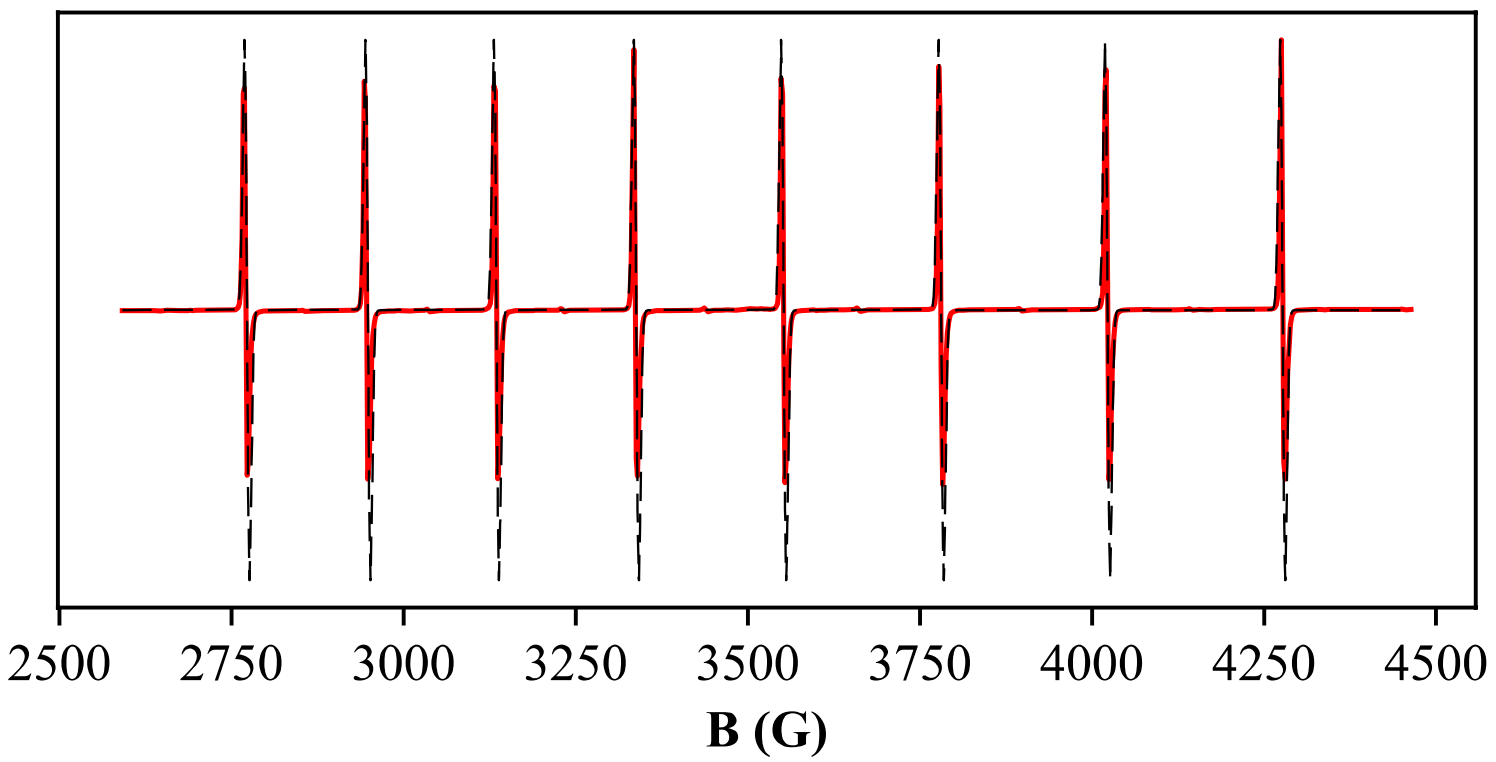

Figure S17. Room-temperature X-band EPR spectrum (red) and simulated spectrum (black dashes) of the products of reaction 12. Signal is present at $g=1.98, A\left({ }^{45} \mathrm{Sc}\right)=214.7 \mathrm{G}$ $\left(\left[\mathrm{Sc}^{\mathrm{II}}\left(\mathrm{NR}_{2}\right)_{3}\right]^{1-}\right)$.

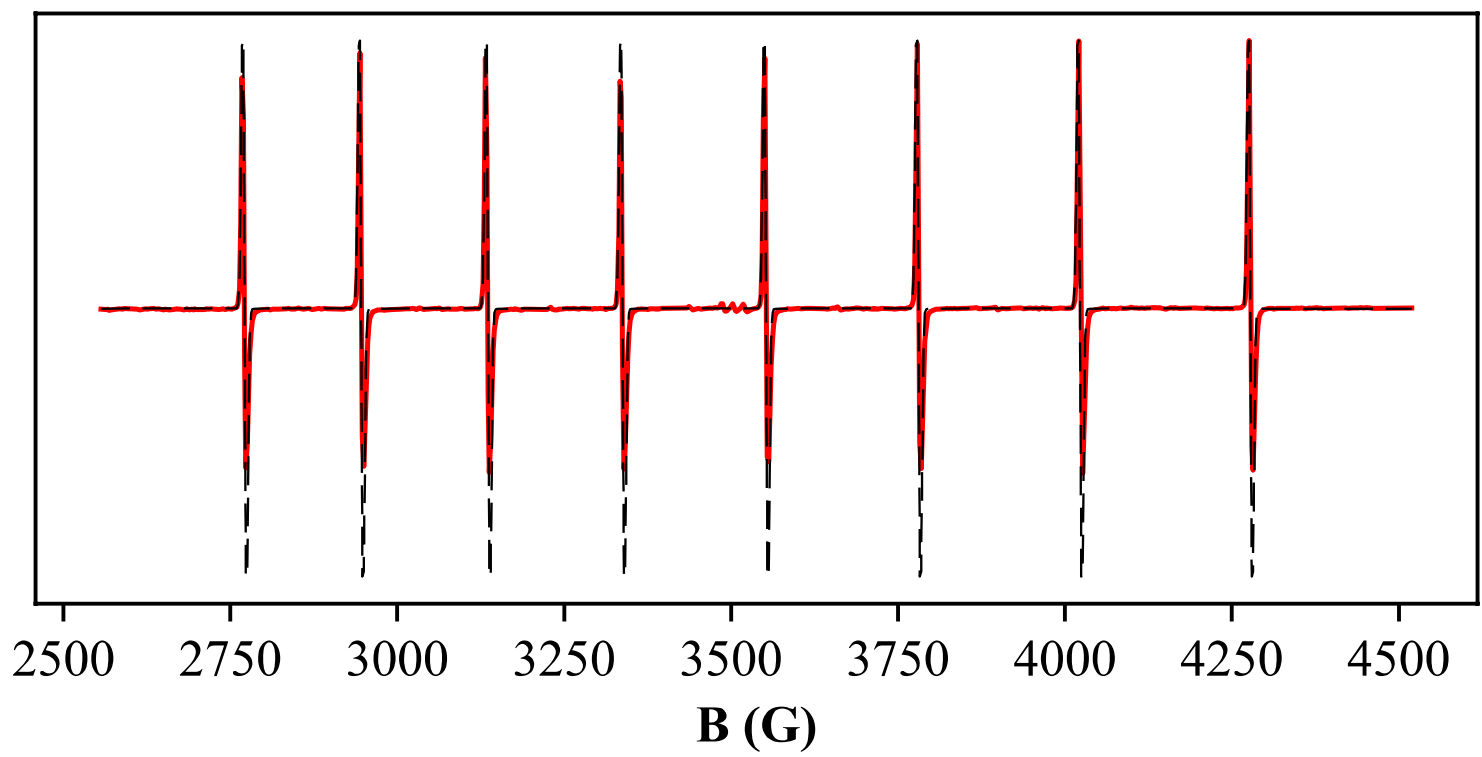

Figure S18. Room-temperature X-band EPR spectrum (red) and simulated spectrum (black dashes) of the products of reaction 13. Signal is present at $g=1.98, A\left({ }^{45} \mathrm{Sc}\right)=214.9 \mathrm{G}$ $\left(\left[\mathrm{Sc}^{\mathrm{II}}\left(\mathrm{NR}_{2}\right)_{3}\right]^{1-}\right)$. Small signals near $3500 \mathrm{G}$ are not consistent with $\left[\mathrm{Y}^{\mathrm{II}}\left(\mathrm{NR}_{2}\right)_{3}\right]^{1-}\left(g=1.97, A\left({ }^{89} \mathrm{Y}\right)\right.$ $=110.5 \mathrm{G})$. 


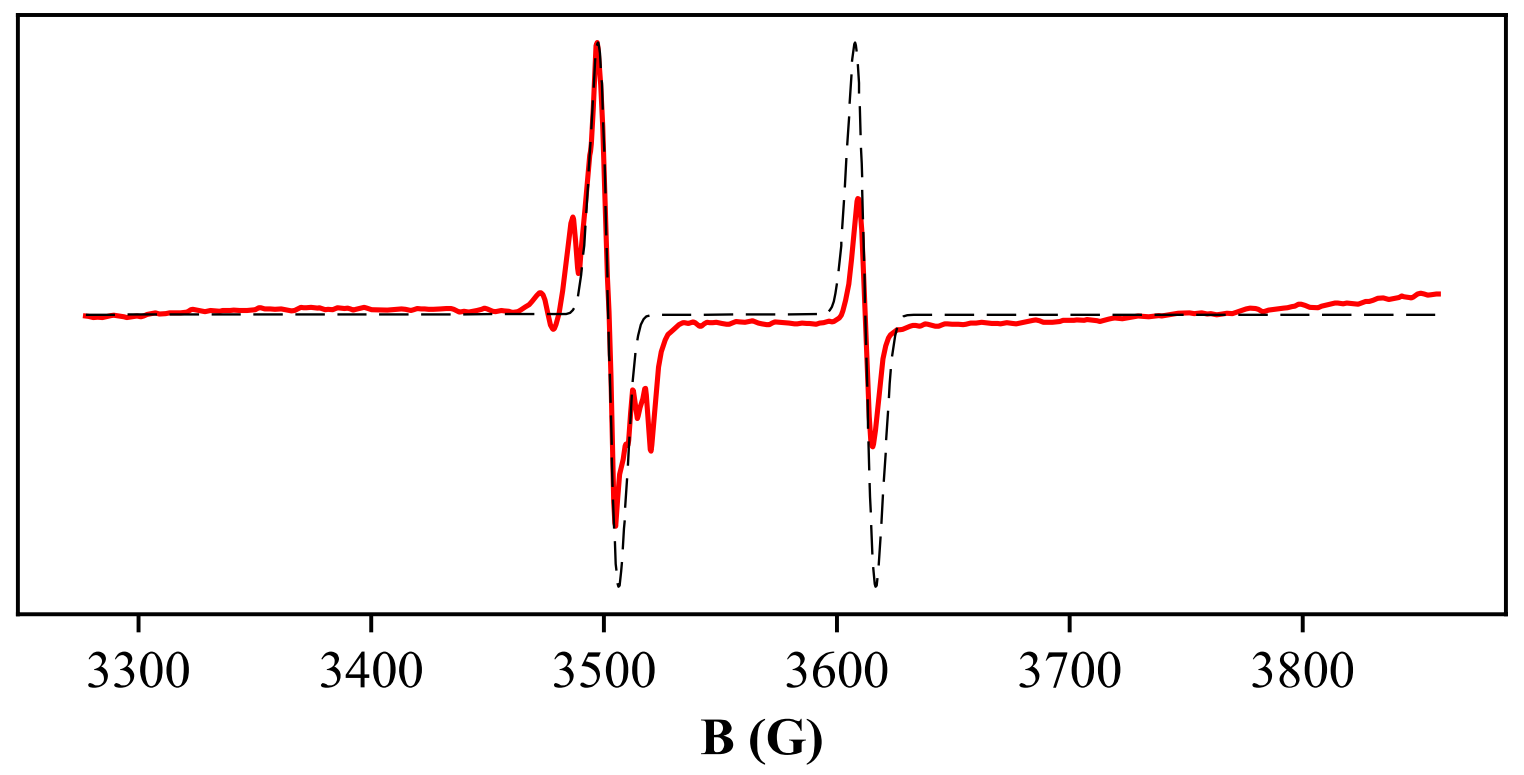

Figure S19. Room-temperature X-band EPR spectrum (red) and simulated spectrum (black dashes) of the products of reaction 14. Signal is present at $g=1.97, A\left({ }^{89} \mathrm{Y}\right)=110.5 \mathrm{G}$ $\left(\left[\mathrm{Y}^{\mathrm{II}}\left(\mathrm{NR}_{2}\right)_{3}\right]^{1-}\right)$ with other, unsimulated signals around $3500 \mathrm{G}$ (unknown species).

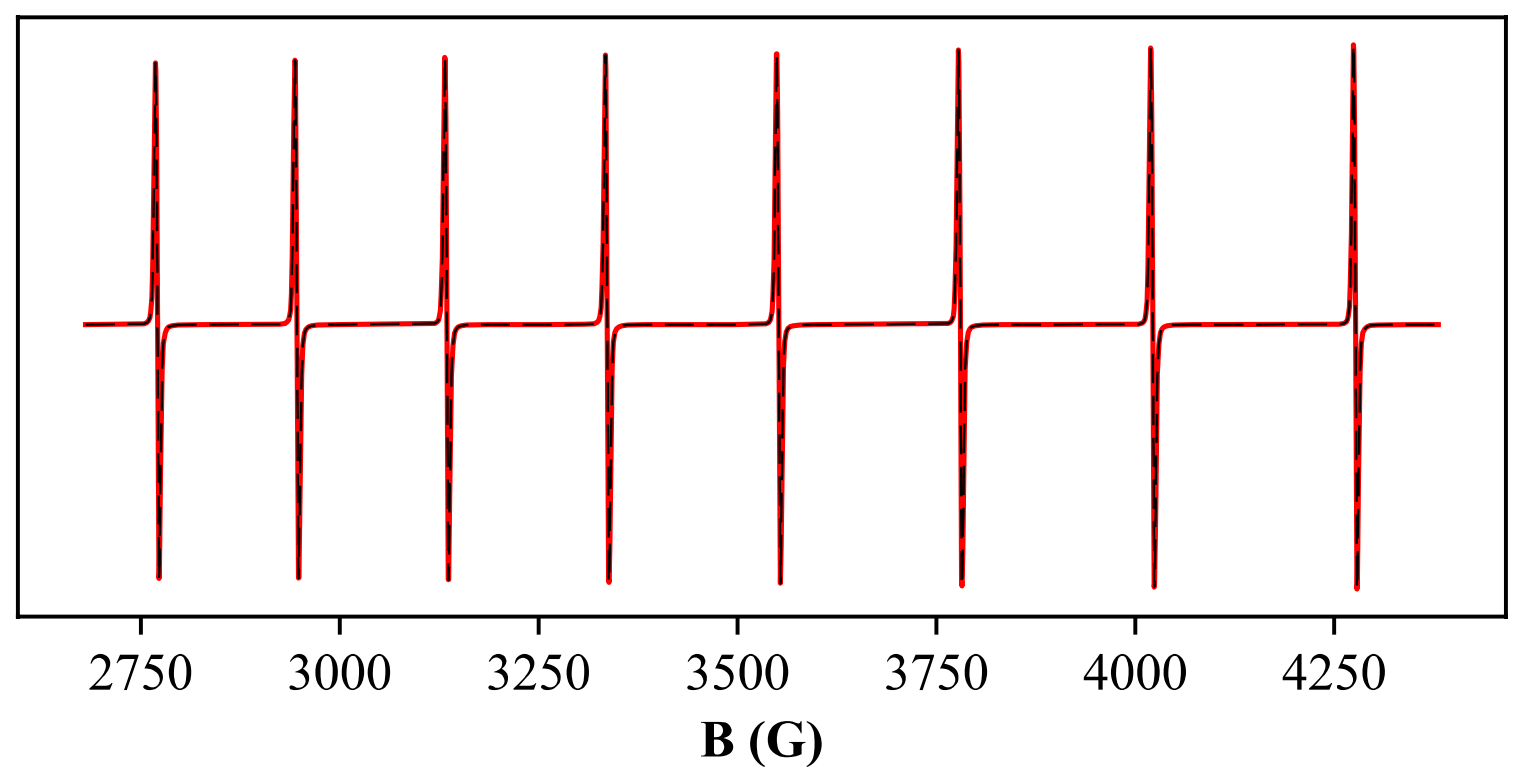

Figure S20. Room-temperature X-band EPR spectrum (red) and simulated spectrum (black dashes) of the products of reaction of $\left[\mathrm{Gd}^{\mathrm{II}}\left(\mathrm{NR}_{2}\right)_{3}\right]^{1-}$ with $\mathrm{Sc}^{\mathrm{III}}\left(\mathrm{NR}_{2}\right)_{3}$. Signal is present at $g=1.98$, $A\left({ }^{45} \mathrm{Sc}\right)=214.9 \mathrm{G}\left(\left[\mathrm{Sc}^{\mathrm{II}}\left(\mathrm{NR}_{2}\right)_{3}\right]^{1-}\right)$. 


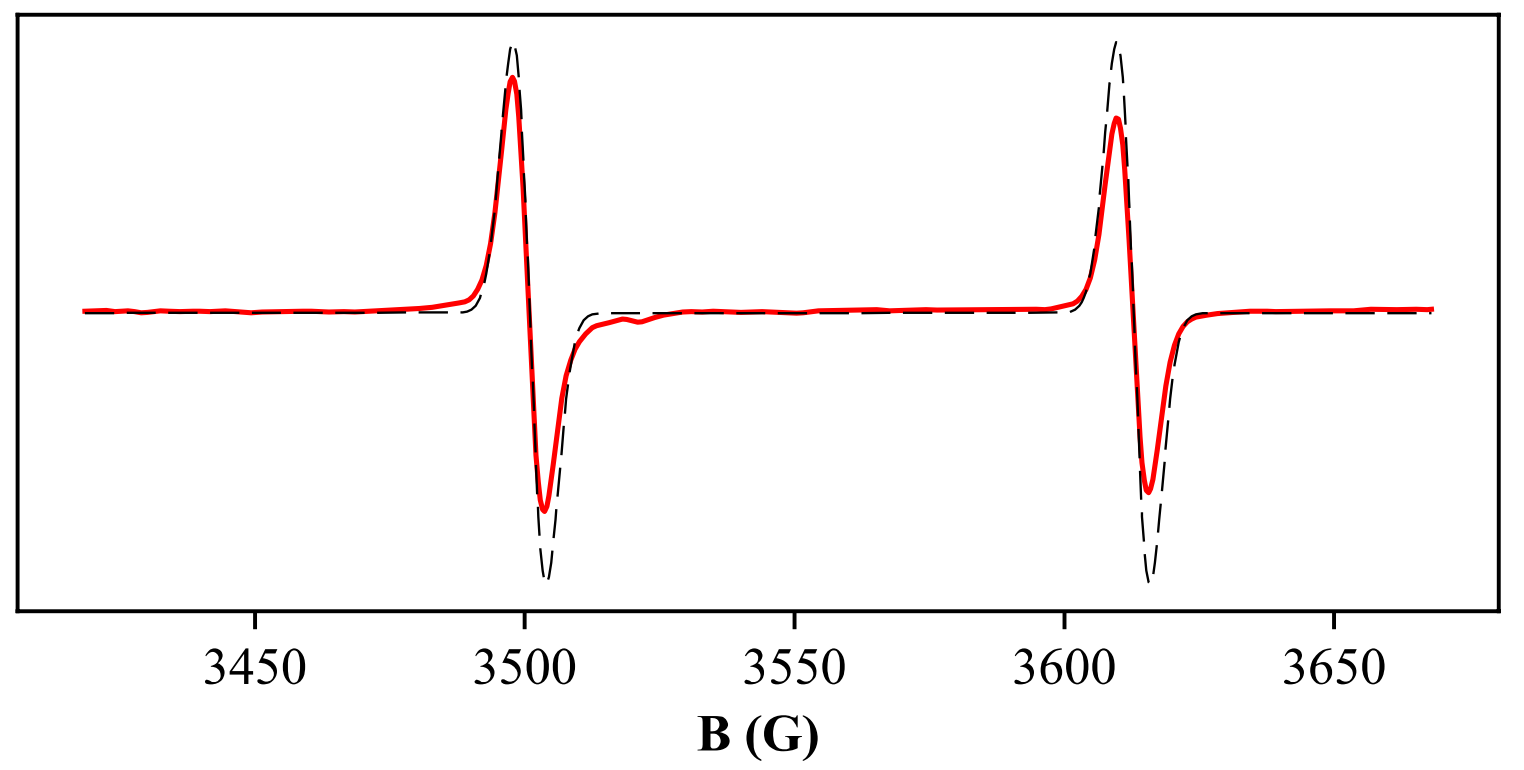

Figure S21. Room-temperature X-band EPR spectrum (red) and simulated spectrum (black dashes) of the products of reaction of $\left[\mathrm{Tb}^{\mathrm{II}}\left(\mathrm{NR}_{2}\right)_{3}\right]^{1-}$ with $\mathrm{Y}^{\mathrm{III}}\left(\mathrm{NR}_{2}\right)_{3}$. Signal is present at $g=1.97$, $A\left({ }^{89} \mathrm{Y}\right)=111.9 \mathrm{G}\left(\left[\mathrm{Y}^{\mathrm{II}}\left(\mathrm{NR}_{2}\right)_{3}\right]^{1-}\right)$.

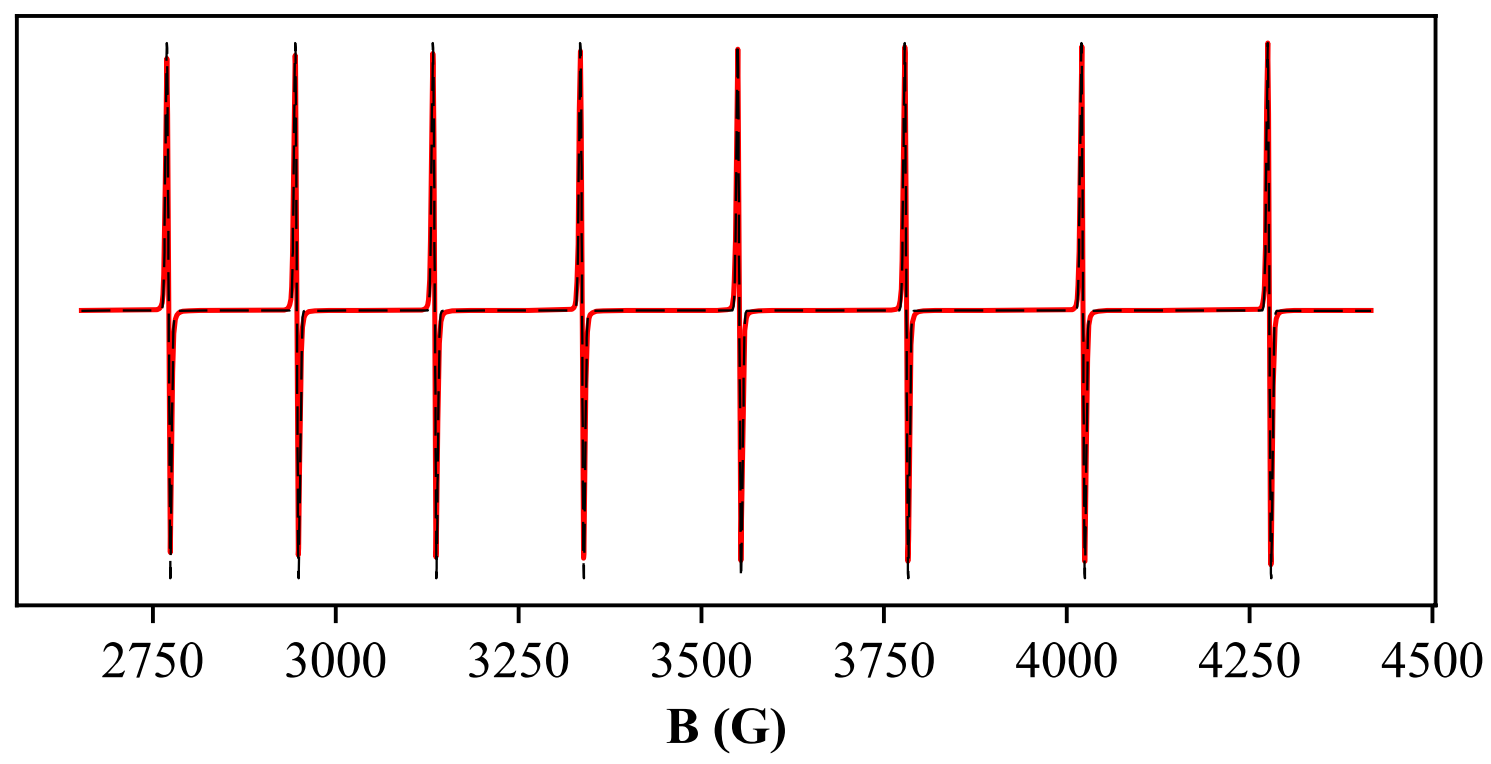

Figure S22. Room-temperature X-band EPR spectrum (red) and simulated spectrum (black dashes) of the products of reaction of $\left[\mathrm{Tb}^{\mathrm{II}}\left(\mathrm{NR}_{2}\right)_{3}\right]^{1-}$ with $\mathrm{Sc}^{\mathrm{III}}\left(\mathrm{NR}_{2}\right)_{3}$. Signal is present at $g=1.98$, $A\left({ }^{45} \mathrm{Sc}\right)=214.8 \mathrm{G}\left(\left[\mathrm{Sc}^{\mathrm{II}}\left(\mathrm{NR}_{2}\right)_{3}\right]^{1-}\right)$. 


\section{$\left[\mathrm{Ln}^{\mathrm{II}} \mathbf{A}_{3}\right]^{1-}$ Reactions with $\mathrm{Ln}^{\mathrm{III}} \mathbf{A}_{3}{ }_{3}$ Complexes \\ $\mathbf{L n}=\mathbf{Y}$}

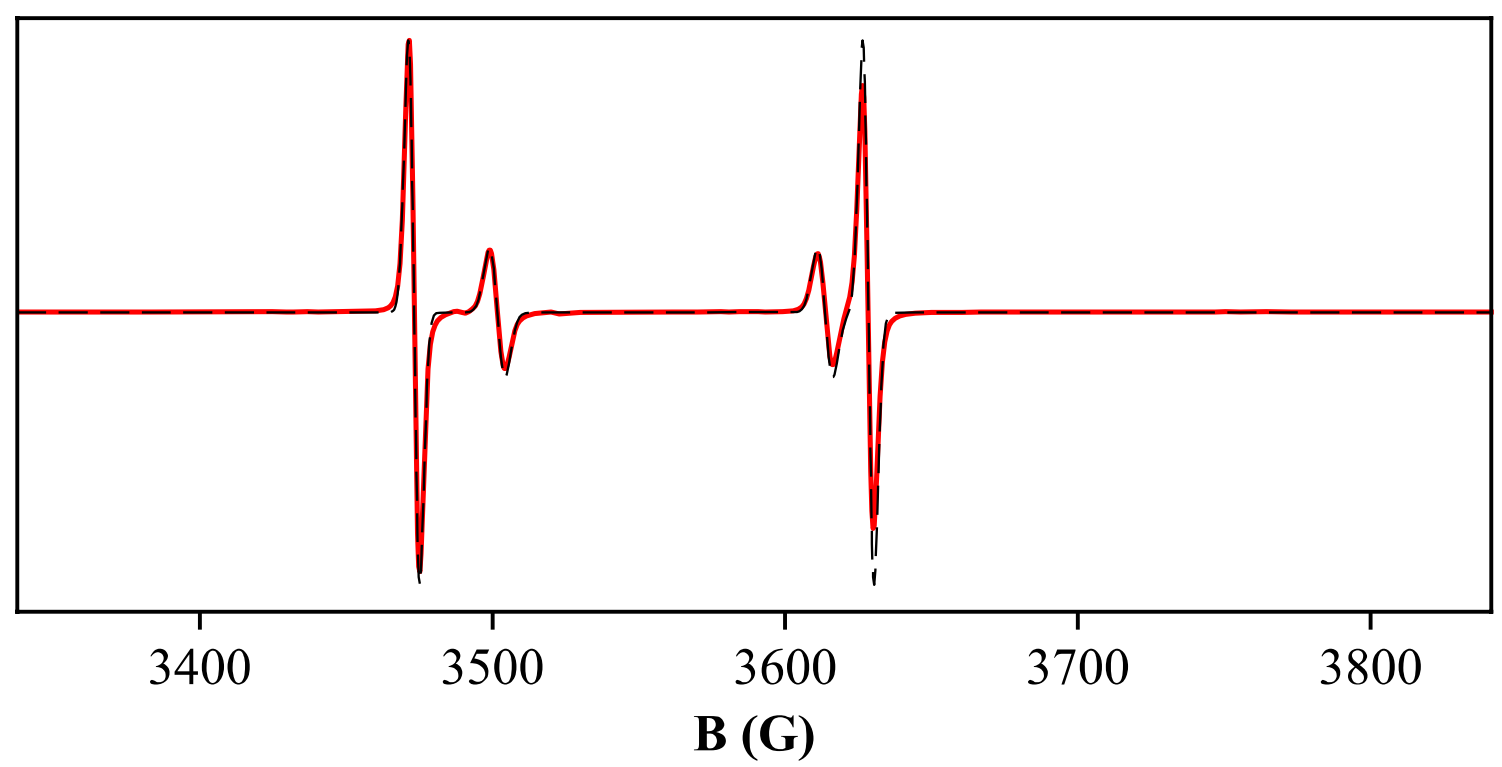

Figure S23. Room-temperature X-band EPR spectrum (red) and simulated spectrum (black dashes) of the products of reaction 20. Signals are present at $g=1.97, A\left({ }^{89} \mathrm{Y}\right)=111.8 \mathrm{G}$ $\left(\left[\mathrm{Y}^{\mathrm{II}}\left(\mathrm{NR}_{2}\right)_{3}\right]^{1-}\right)$ and $g=1.98, A\left({ }^{89} \mathrm{Y}\right)=155.1 \mathrm{G}\left(\left[\mathrm{Y}^{\mathrm{II}}\left(\mathrm{OAr}^{\prime}\right)_{3}\right]^{1-}\right)$.

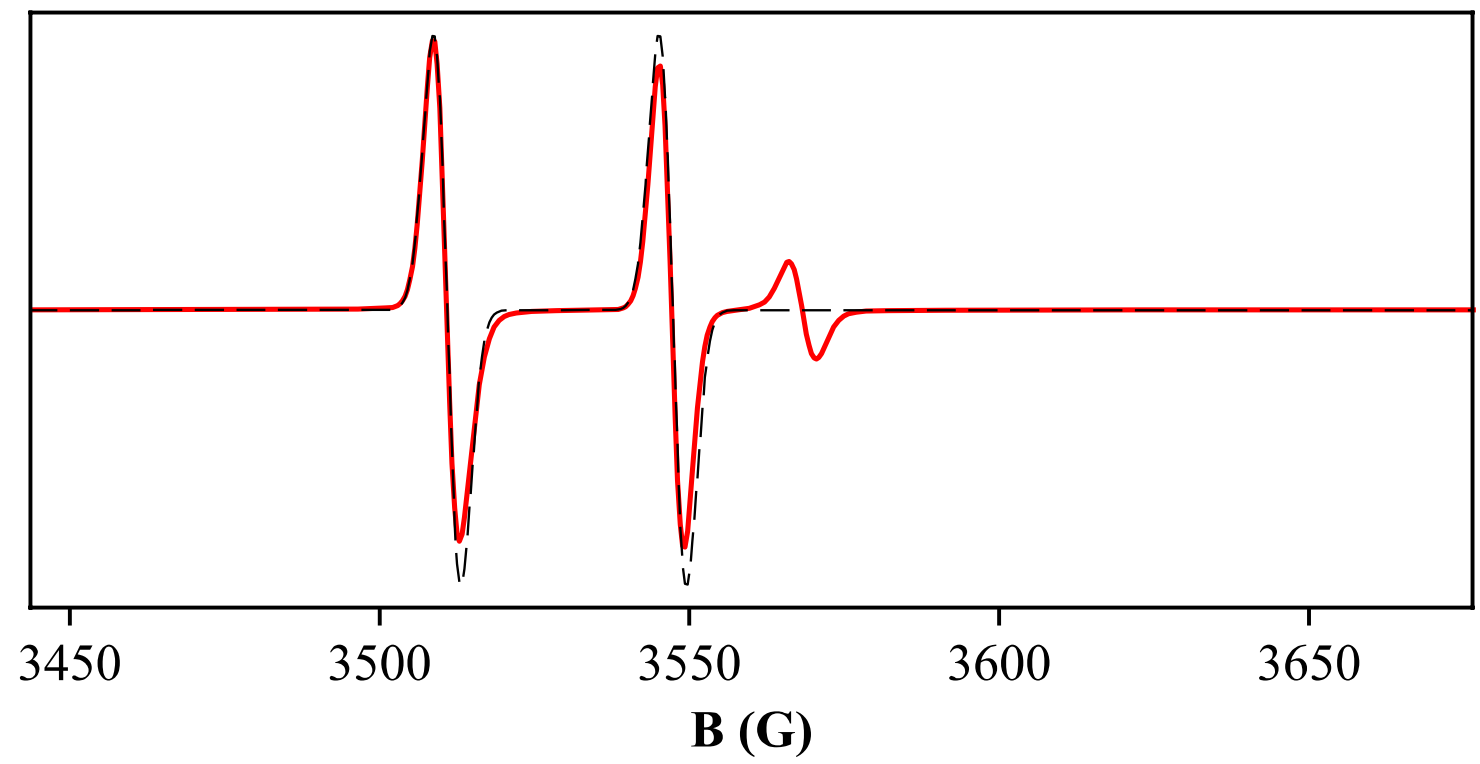

Figure S24. Room-temperature X-band EPR spectrum (red) and simulated spectrum (black dashes) of the products of reaction 17. Signals are present at $g=1.99, A\left({ }^{89} \mathrm{Y}\right)=36.5 \mathrm{G}\left(\left[\mathrm{Y}^{\mathrm{II}} \mathrm{Cp}^{\prime}{ }_{3}\right]^{1-}\right)$ and $\sim 3575 \mathrm{G}$ (an unknown species). 


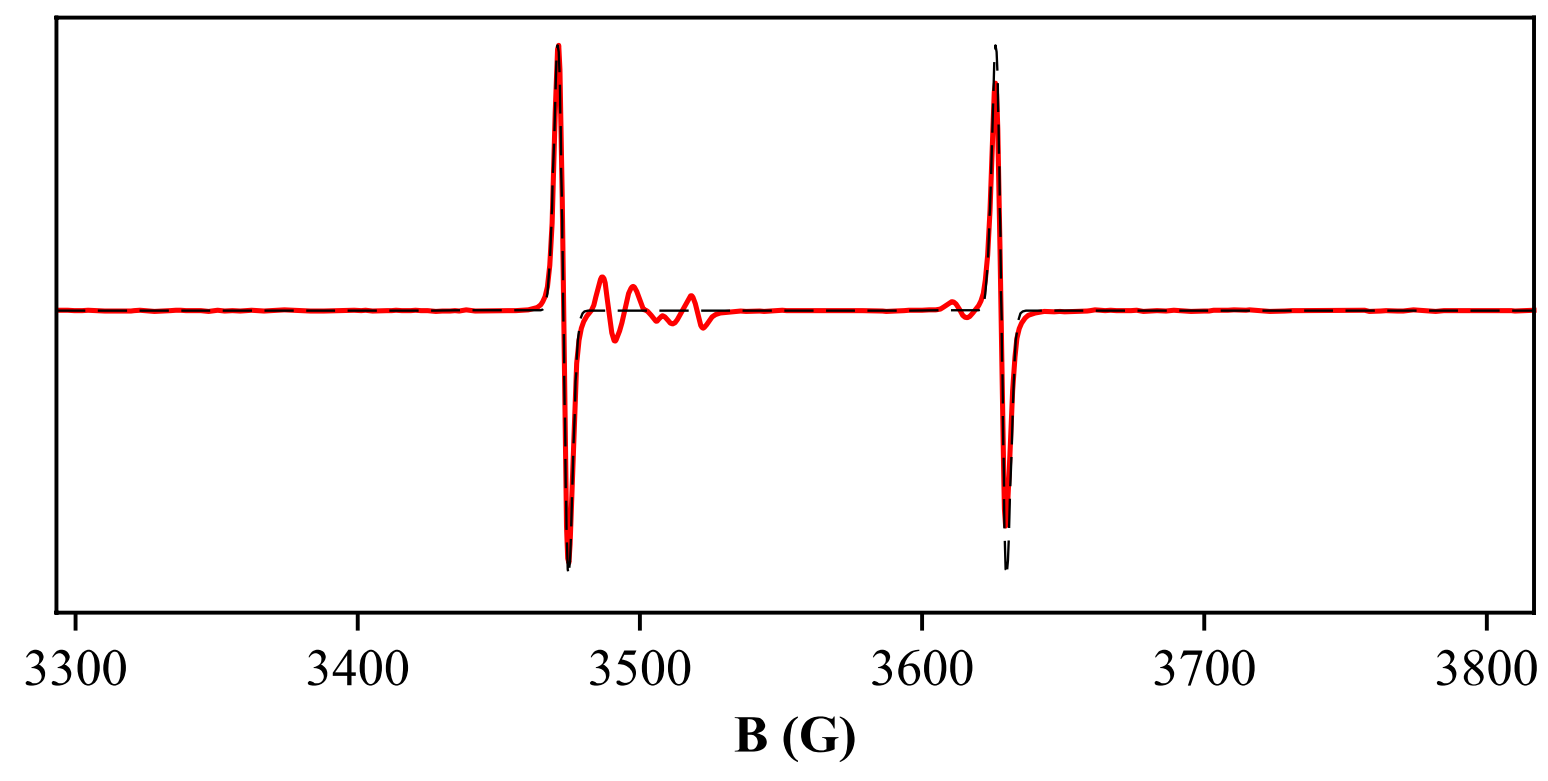

Figure S25. Room-temperature X-band EPR spectrum (red) and simulated spectrum (black dashes) of the products of reaction 19. Signals are present at $g=1.98, A\left({ }^{89} \mathrm{Y}\right)=155.2 \mathrm{G}$ $\left(\left[\mathrm{Y}^{\mathrm{II}}(\mathrm{OAr})_{3}\right]^{1-}\right.$ ) and $\sim 3500 \mathrm{G}$ (an unknown species).

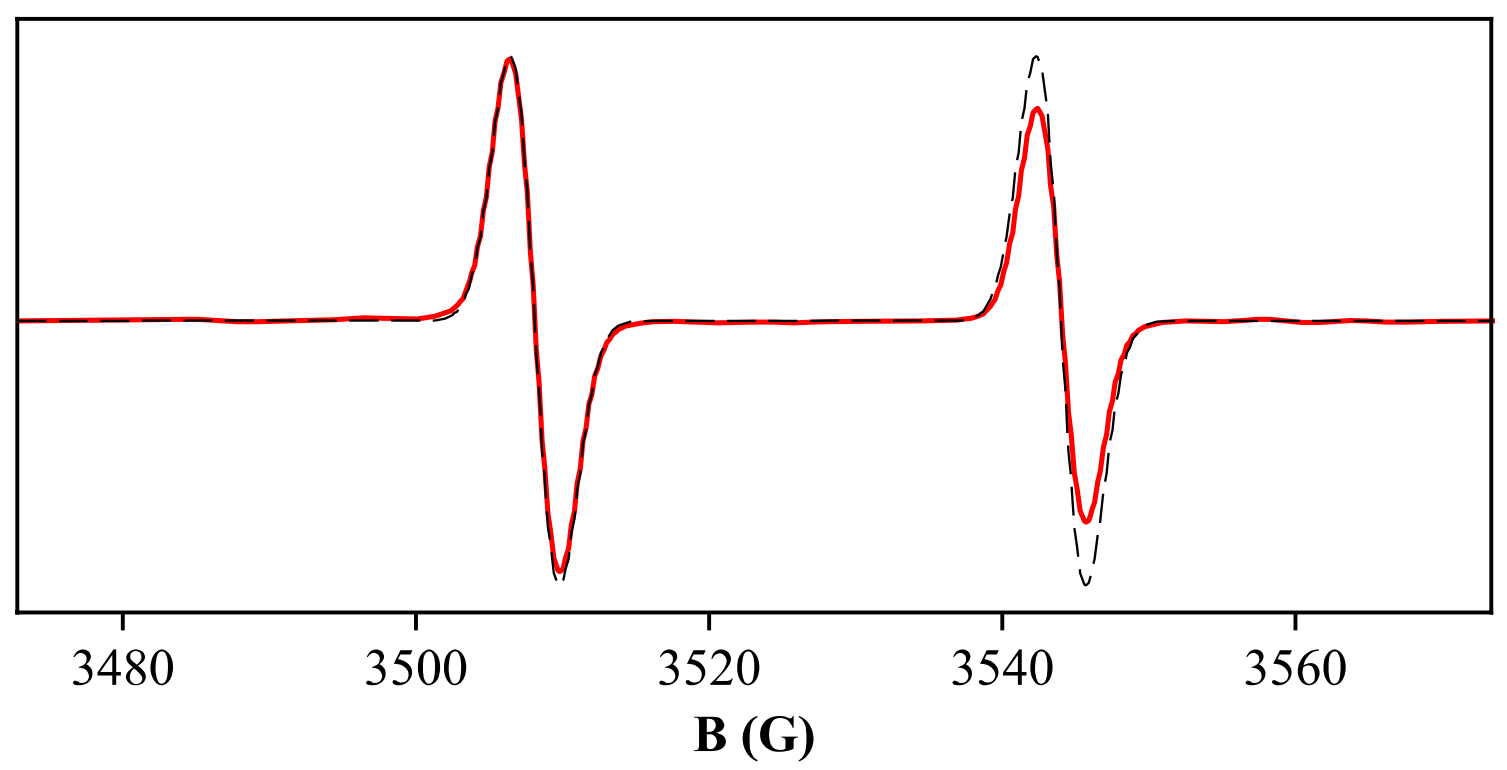

Figure S26. Room-temperature X-band EPR spectrum (red) and simulated spectrum (black dashes) of the products of reaction 18. Signals are present at $g=1.99, A\left({ }^{89} \mathrm{Y}\right)=35.9 \mathrm{G}\left(\left[\mathrm{Y}^{\mathrm{II}} \mathrm{Cp}^{\prime}{ }_{3}\right]^{1-}\right)$. 


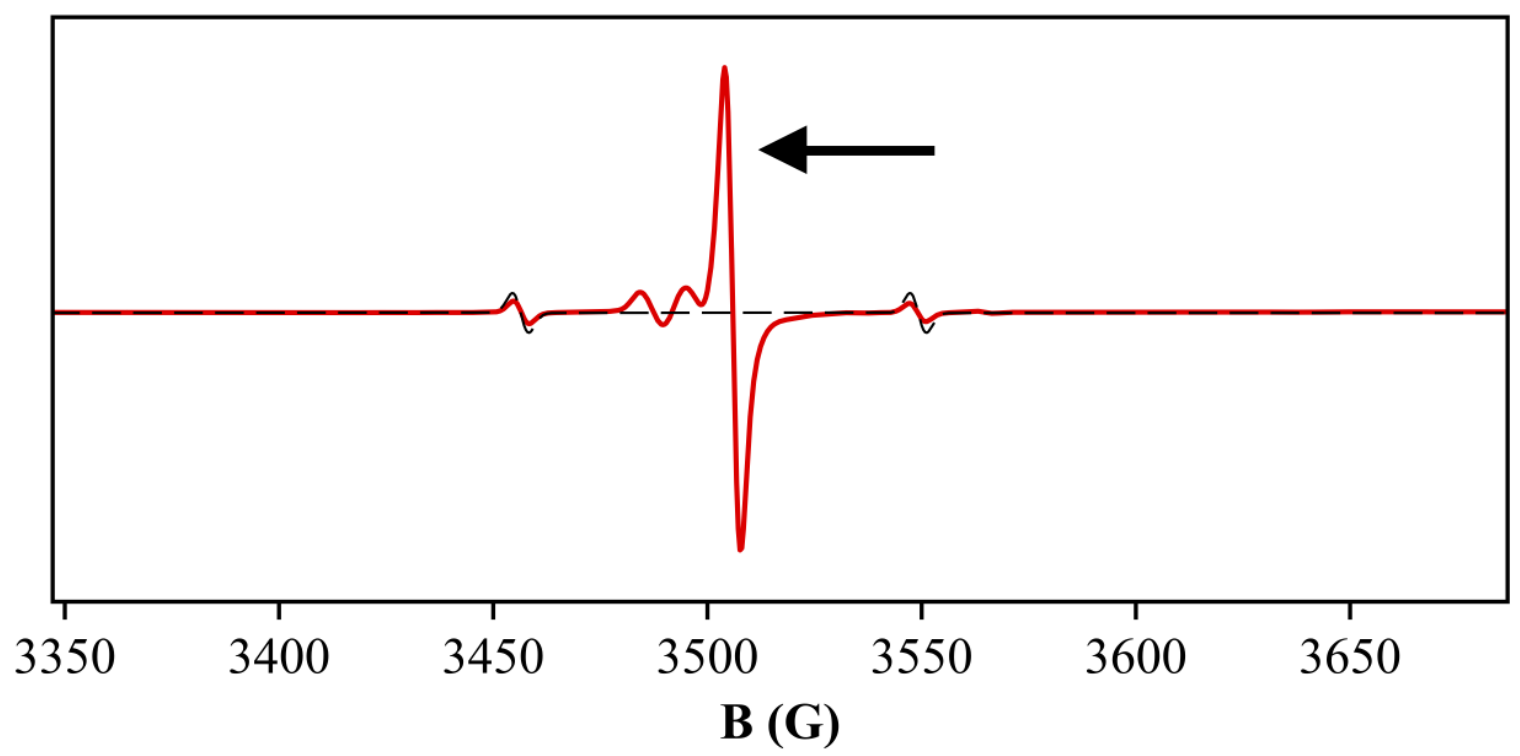

Figure S27. Room-temperature X-band EPR spectrum (red) and simulated spectrum (black dashes) of the products of reaction 15. Signals are present at $g=2.00$ (likely electride, labeled with a black arrow) and $g=2.00, A=92.8 \mathrm{G}$ (the highest $A$ value that could be simulated for this data, an unknown Y(II) species).

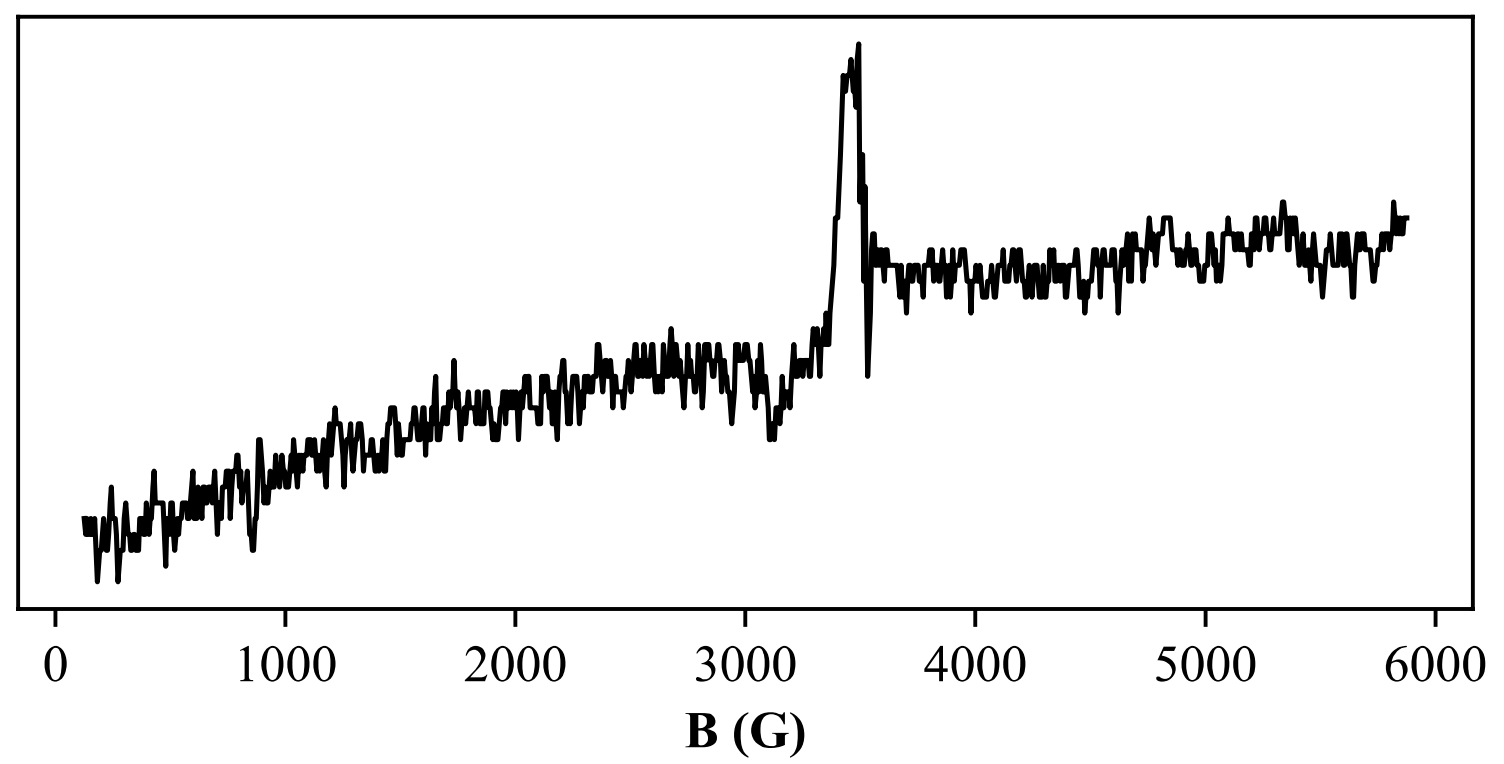

Figure S28. Room-temperature X-band EPR spectrum of the products of reaction 16. Signal is present at $\sim 3500 \mathrm{G}$ (unattributable to any $\mathrm{Y}(\mathrm{II})$ species). 
$\operatorname{Ln}=\mathbf{S c}$

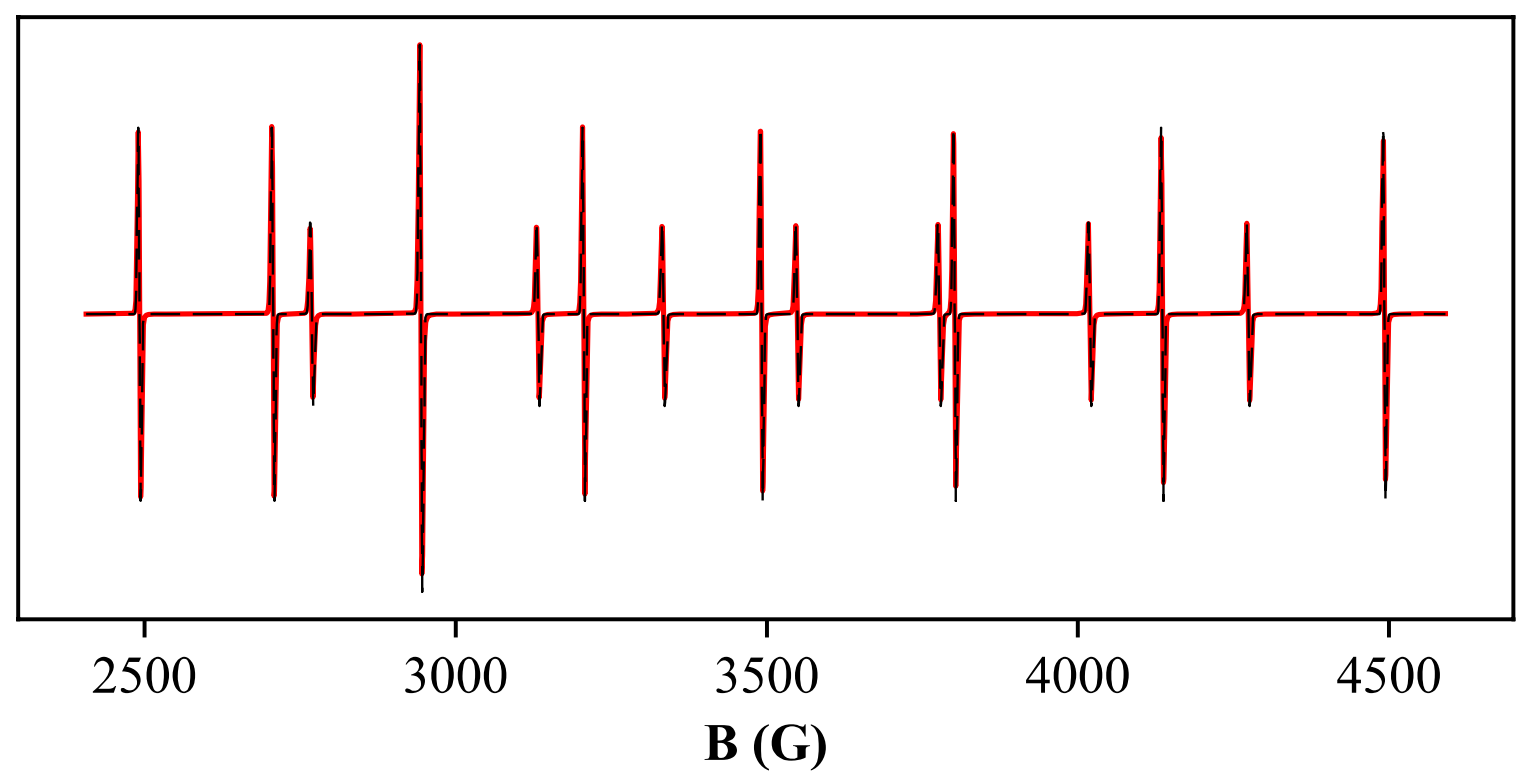

Figure S29. Room-temperature X-band EPR spectrum (red) and simulated spectrum (black dashes) of the products of reaction 21 in the forward direction. Signals are present at $g=1.98$, $A\left({ }^{45} \mathrm{Sc}\right)=214.8 \mathrm{G}\left(\left[\mathrm{Sc}^{\mathrm{II}}\left(\mathrm{NR}_{2}\right)_{3}\right]^{1-}\right)$ and $g=1.99, A\left({ }^{45} \mathrm{Sc}\right)=285.3 \mathrm{G}\left(\left[\mathrm{Sc}^{\mathrm{II}}\left(\mathrm{OAr}^{\prime}\right)_{3}\right]^{1-}\right)$.

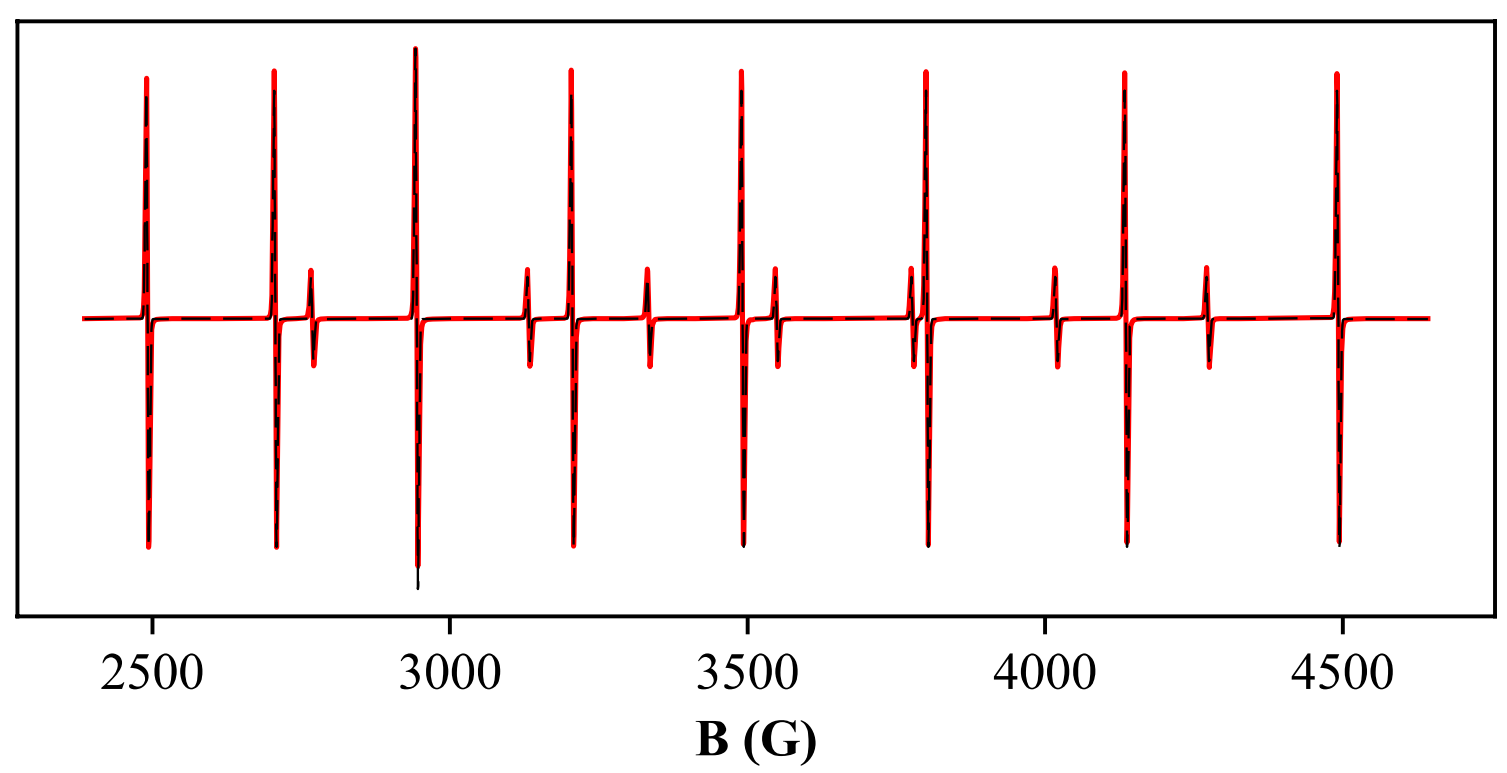

Figure S30. Room-temperature X-band EPR spectrum (red) and simulated spectrum (black dashes) of the products of reaction 21 in the reverse direction. Signals are present at $g=1.98$, $A\left({ }^{45} \mathrm{Sc}\right)=214.8 \mathrm{G}\left(\left[\mathrm{Sc}^{\mathrm{II}}\left(\mathrm{NR}_{2}\right)_{3}\right]^{1-}\right)$ and $g=1.99, A\left({ }^{45} \mathrm{Sc}\right)=285.4 \mathrm{G}\left(\left[\mathrm{Sc}^{\mathrm{II}}\left(\mathrm{OAr}^{\prime}\right)_{3}\right]^{1-}\right)$. 


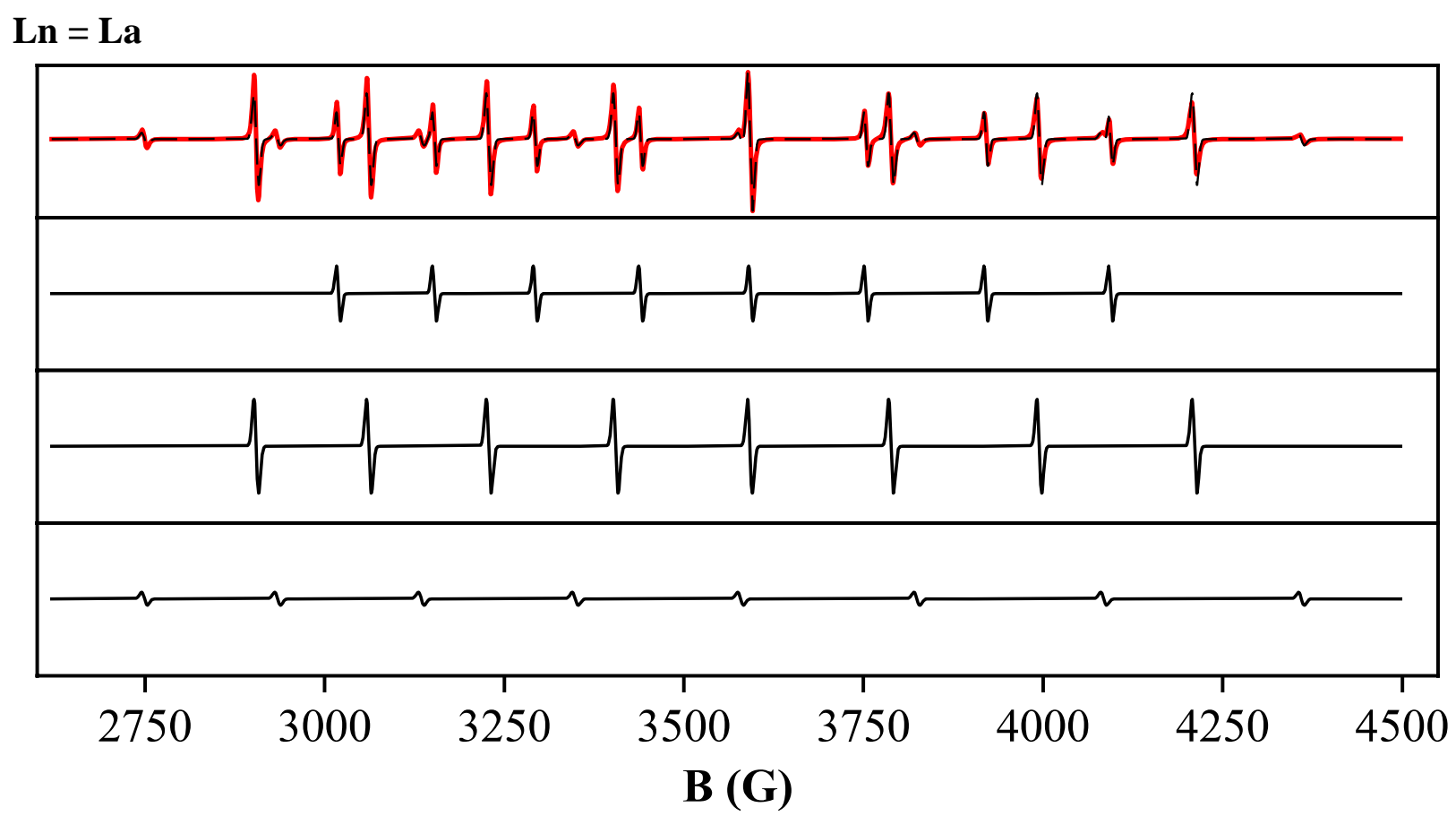

Figure S31. Room-temperature X-band EPR spectrum (red, first panel), sum of simulated signals (black dashes, first panel), and individual simulated signals (black) of the products of reaction 22. Signals are present at $g=1.97, A\left({ }^{139} \mathrm{La}\right)=153.4 \mathrm{G}\left(\left[\mathrm{La}^{\mathrm{II}} \mathrm{Cp}_{3}^{\prime}\right]^{1-}\right.$, second panel $), g_{A}=1.96, A_{A}\left({ }^{139} \mathrm{La}\right)$ $=186.5 \mathrm{G}(\mathbf{L a}-\mathbf{A}$, third panel $)$ and $g_{B}=1.96, A_{B}\left({ }^{139} \mathrm{La}\right)=229.8 \mathrm{G}(\mathbf{L a}-\mathbf{B}$, fourth panel $)$.

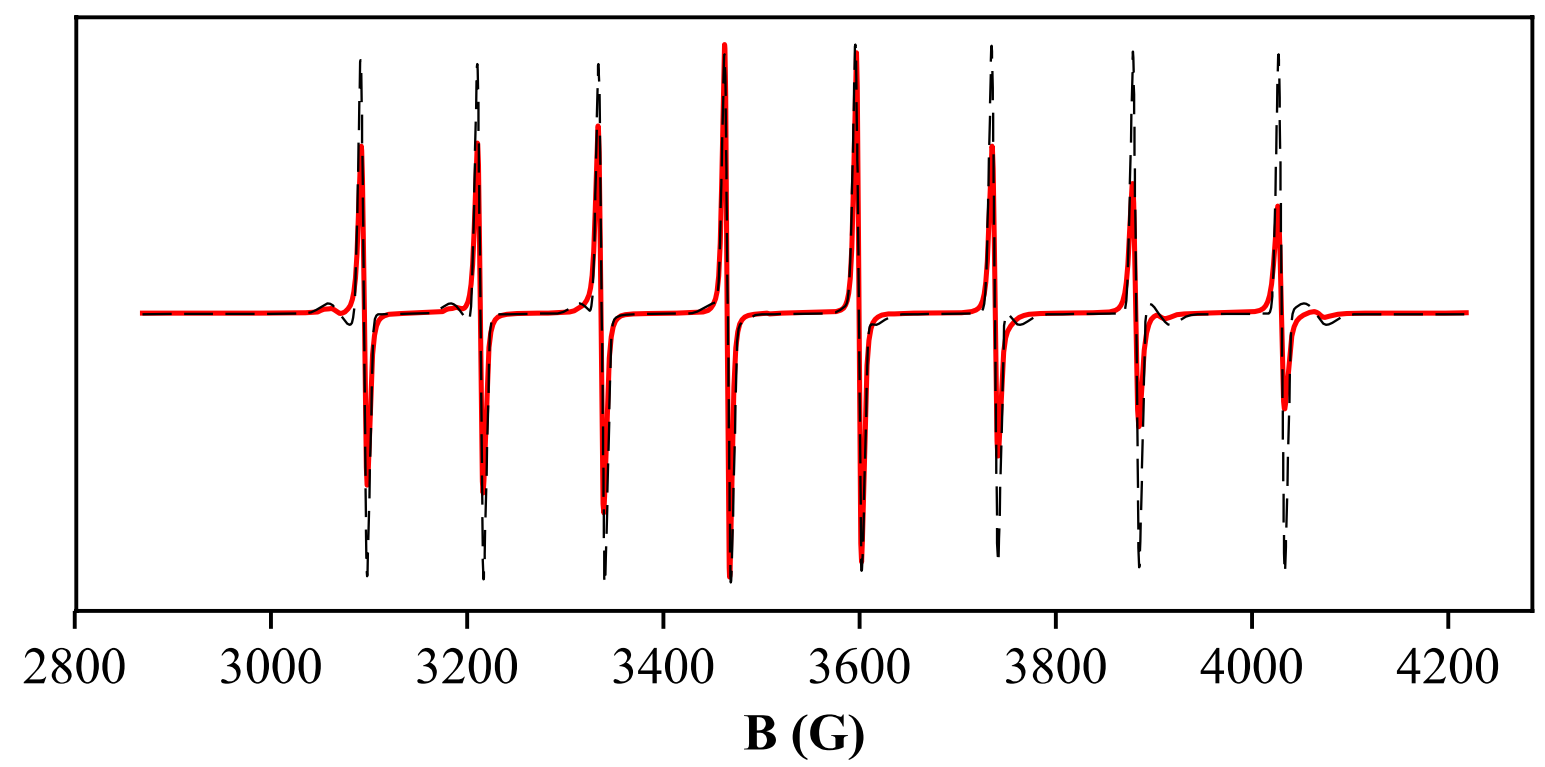

Figure S32. Room-temperature X-band EPR spectrum (red) and simulated spectrum (black dashes) of the products of reaction 24 . Signals are present at $g=1.97, A\left({ }^{139} \mathrm{La}\right)=133.6 \mathrm{G}$ $\left(\left[\mathrm{La}^{\mathrm{II}} \mathrm{Cp}^{\prime \prime}{ }_{3}\right]^{1-}\right)$ and $g=1.96, A\left({ }^{139} \mathrm{La}\right)=142.0 \mathrm{G}$ (an unknown La(II) species). 


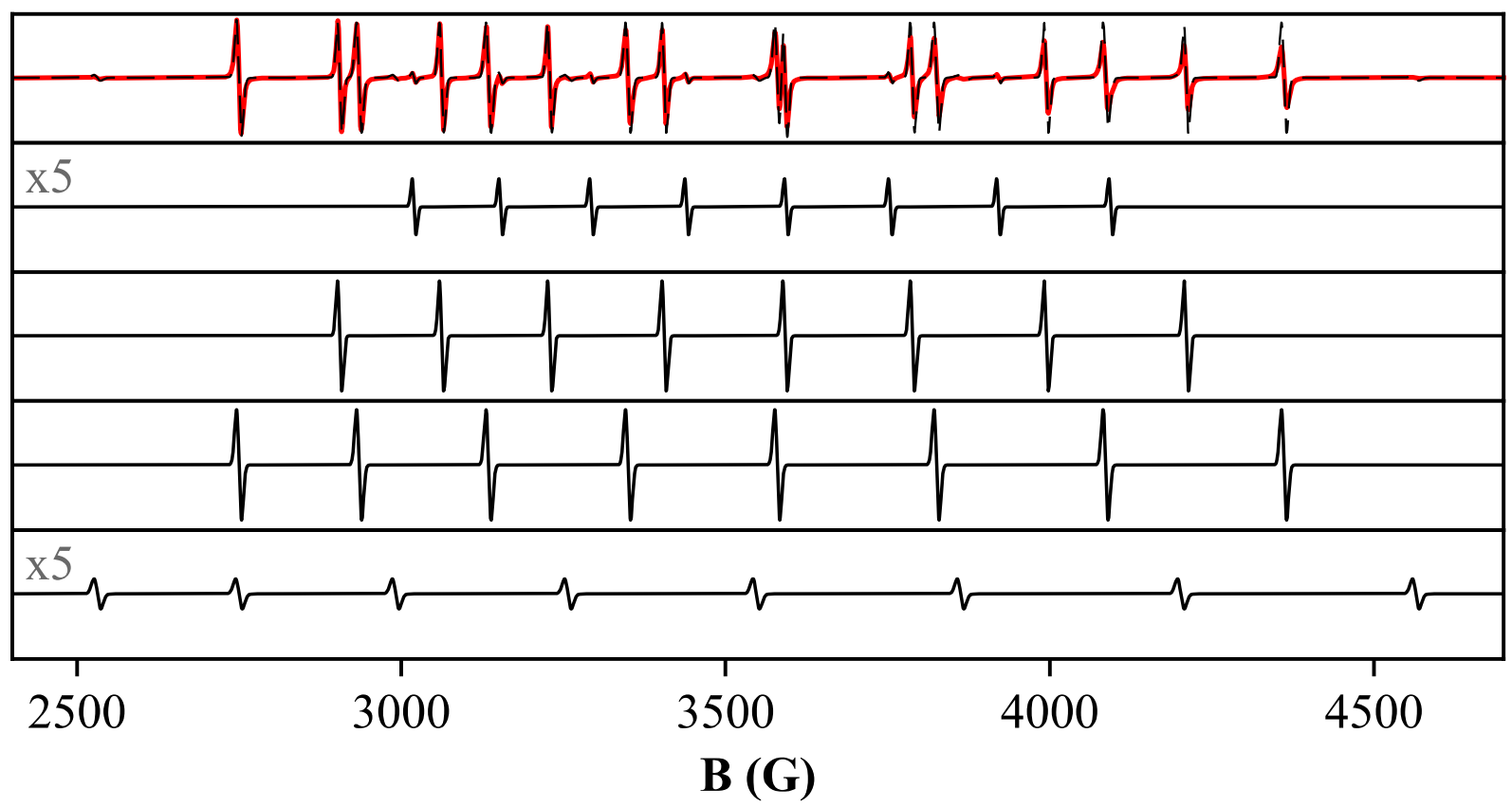

Figure S33. Room-temperature X-band EPR spectrum (red, first panel), sum of simulated signals (black dashes, first panel), and individual simulated signals (black) of the products of reaction 23. Signals are present at $g=1.97, A=153.5 \mathrm{G}\left(\left[\mathrm{La}^{\mathrm{II}} \mathrm{Cp}_{3}^{\prime}\right]^{1-}\right.$, second panel, magnified $\left.5 \mathrm{x}\right), g_{A}=1.96$, $A_{A}\left({ }^{139} \mathrm{La}\right)=186.4 \mathrm{G}(\mathbf{L a}-\mathbf{A}$, third panel $), g_{B}=1.96, A_{B}\left({ }^{139} \mathrm{La}\right)=230.0 \mathrm{G}(\mathbf{L a}-\mathbf{B}$, fourth panel $)$, and $g=1.96, A\left({ }^{139} \mathrm{La}\right)=290.0 \mathrm{G}\left(\left[\mathrm{La}^{\mathrm{II}} \mathrm{Cp}^{\text {tet }} 3\right]^{1-}\right.$, fifth panel, magnified $\left.5 \mathrm{x}\right)$.

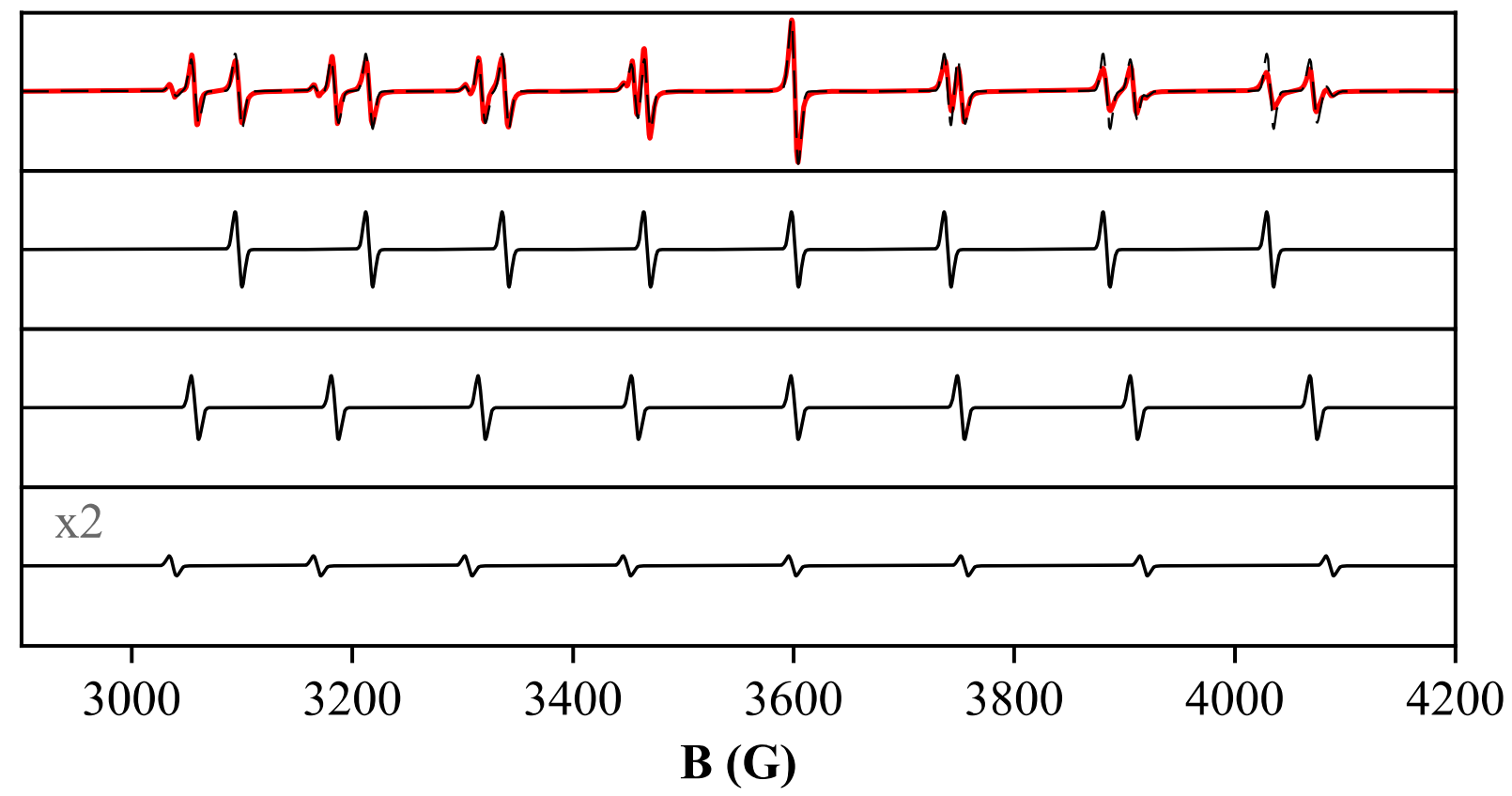

Figure S34. Room-temperature X-band EPR spectrum (red, first panel), sum of simulated signals (black dashes, first panel), and individual simulated signals (black) of the products of reaction 25. Signals are present at $g=1.96, A\left({ }^{139} \mathrm{La}\right)=133.6 \mathrm{G}\left(\left[\mathrm{La}^{\mathrm{II}} \mathrm{Cp}^{\prime \prime}{ }_{3}\right]^{1-}\right.$, second panel $), g_{C}=1.96, A_{C}\left({ }^{139} \mathrm{La}\right)$ $=144.8 \mathrm{G}(\mathbf{L a}-\mathbf{C}$, third panel $)$ and $g_{D}=1.96, A_{D}\left({ }^{139} \mathrm{La}\right)=149.8 \mathrm{G}(\mathbf{L a}-\mathbf{D}$, fourth panel, magnified $2 \mathrm{x})$. 


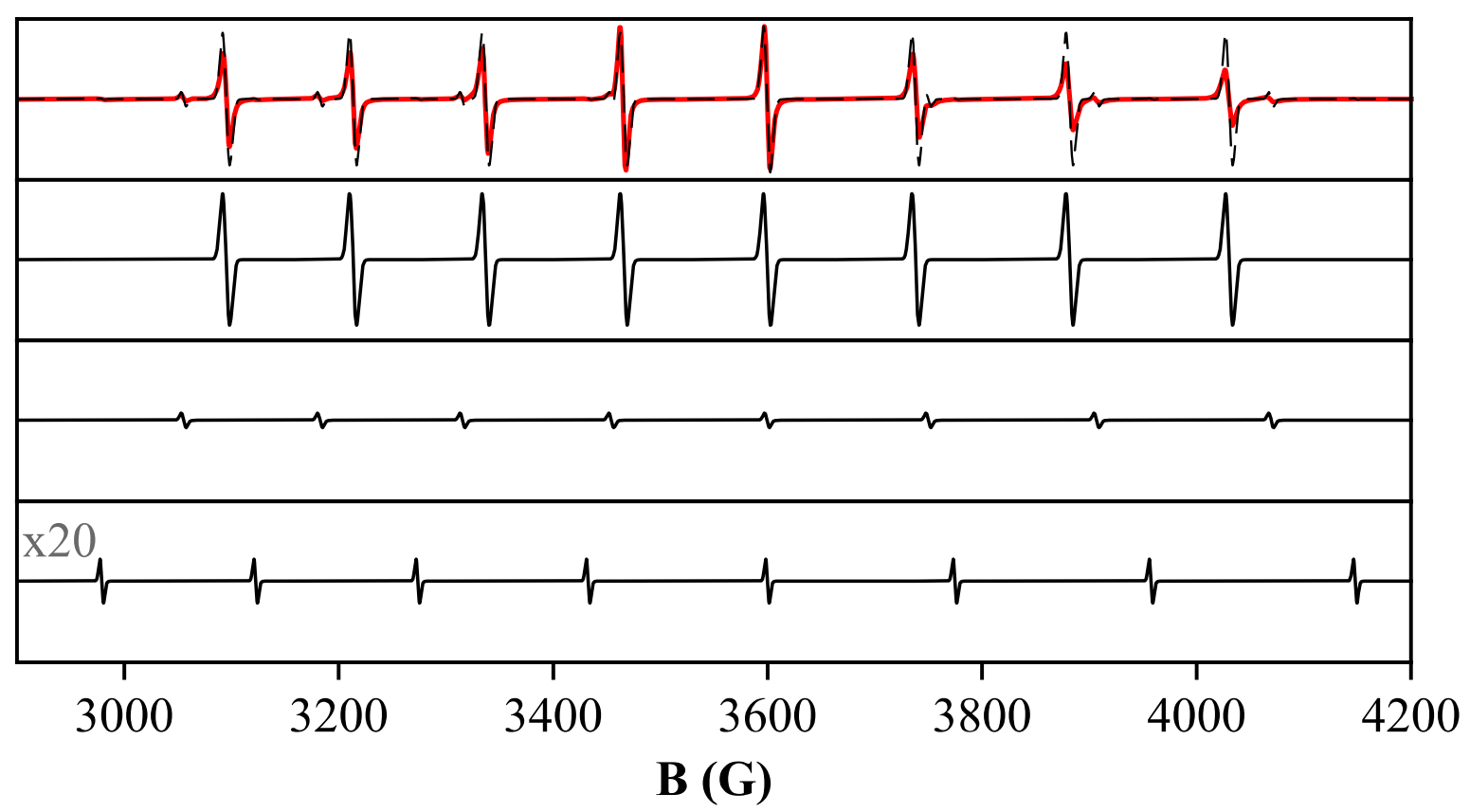

Figure S35. Room-temperature X-band EPR spectrum (red, first panel) sum of simulated signals (black dashes, first panel) and individual simulated signals (black) of the products of reaction of $\left[\mathrm{La}^{\mathrm{II}} \mathrm{Cp}^{\prime \prime}{ }_{3}\right]^{1-}$ with $\mathrm{La}^{\mathrm{III}} \mathrm{Cp}^{\text {tet }}{ }_{3}$. Signals are present at $g=1.97, A\left({ }^{139} \mathrm{La}\right)=133.6 \mathrm{G}\left(\left[\mathrm{La}^{\mathrm{II}} \mathrm{Cp}^{\prime \prime}{ }_{3}\right]^{1-}\right.$, second panel), $g_{1}=1.96, A_{l}\left({ }^{139} \mathrm{La}\right)=144.8 \mathrm{G}$ (an unknown $\mathrm{La}(\mathrm{II})$ species, third panel) and $g_{2}=$ $1.96, A_{2}\left({ }^{139} \mathrm{La}\right)=166.9 \mathrm{G}($ an unknown $\mathrm{La}(\mathrm{II})$ species, fourth panel, magnified $20 \mathrm{x})$.

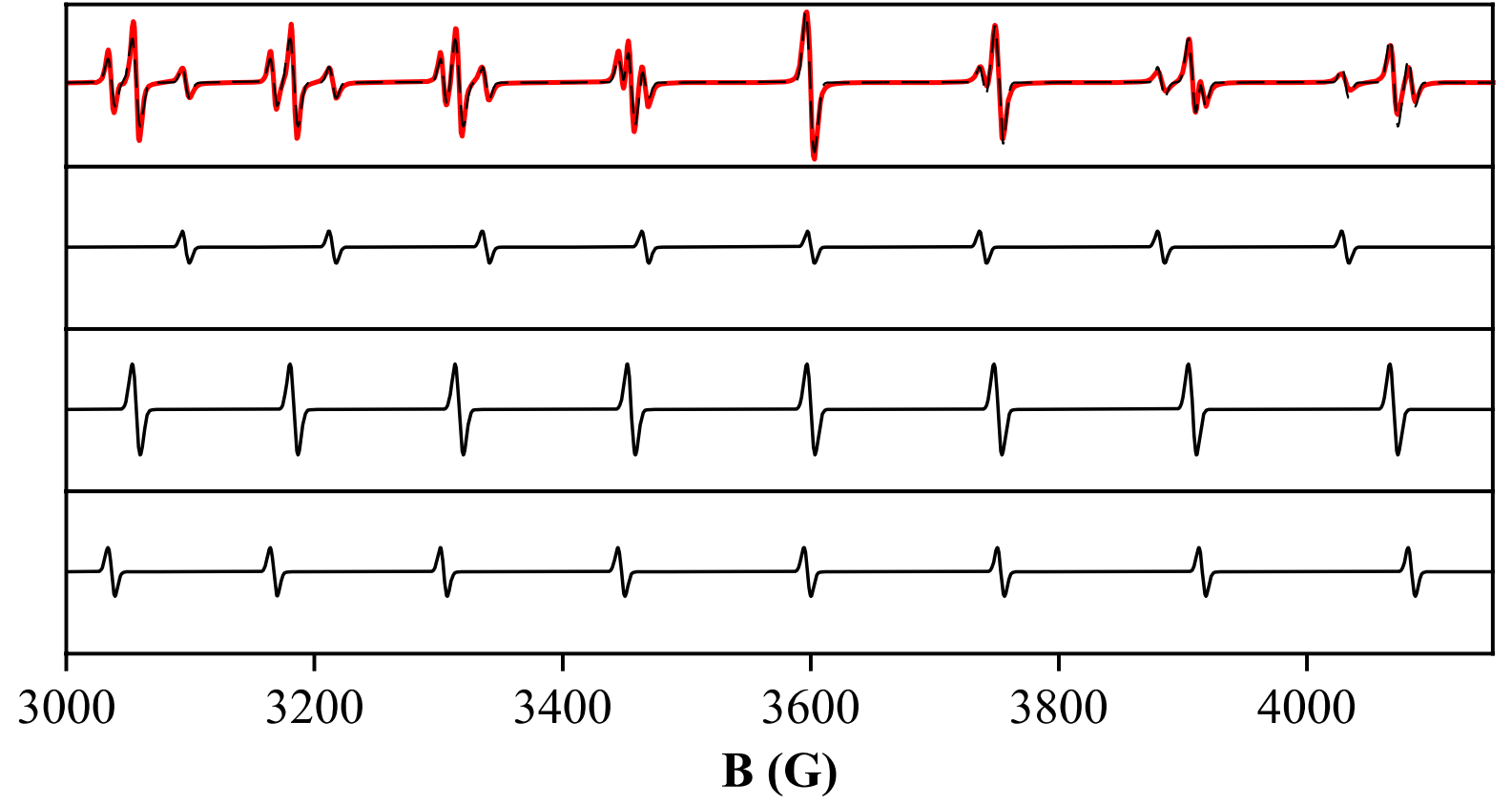

Figure S36. Room-temperature X-band EPR spectrum (red, first panel) sum of simuated signals (black dashes, first panel), and individual simulated signals (black) of the products of reaction 25 in the reverse direction. Signals are present at $g=1.96, A\left({ }^{139} \mathrm{La}\right)=133.5 \mathrm{G}\left(\left[\mathrm{La}^{\mathrm{II}} \mathrm{Cp}^{\prime \prime}\right]^{1-}\right.$, second panel $), g_{C}=1.96, A_{C}\left({ }^{139} \mathrm{La}\right)=144.8 \mathrm{G}(\mathbf{L a}-\mathbf{C}$, third panel $)$ and $g_{D}=1.97, A_{D}\left({ }^{139} \mathrm{La}\right)=149.7 \mathrm{G}(\mathbf{L a}-$ D, fourth panel). 
$\left[\mathrm{La}^{\mathrm{II}} \mathrm{Cp}^{\prime \prime}\right]^{1-}+\mathrm{KA}:$ Ligand Exchange Reactions.

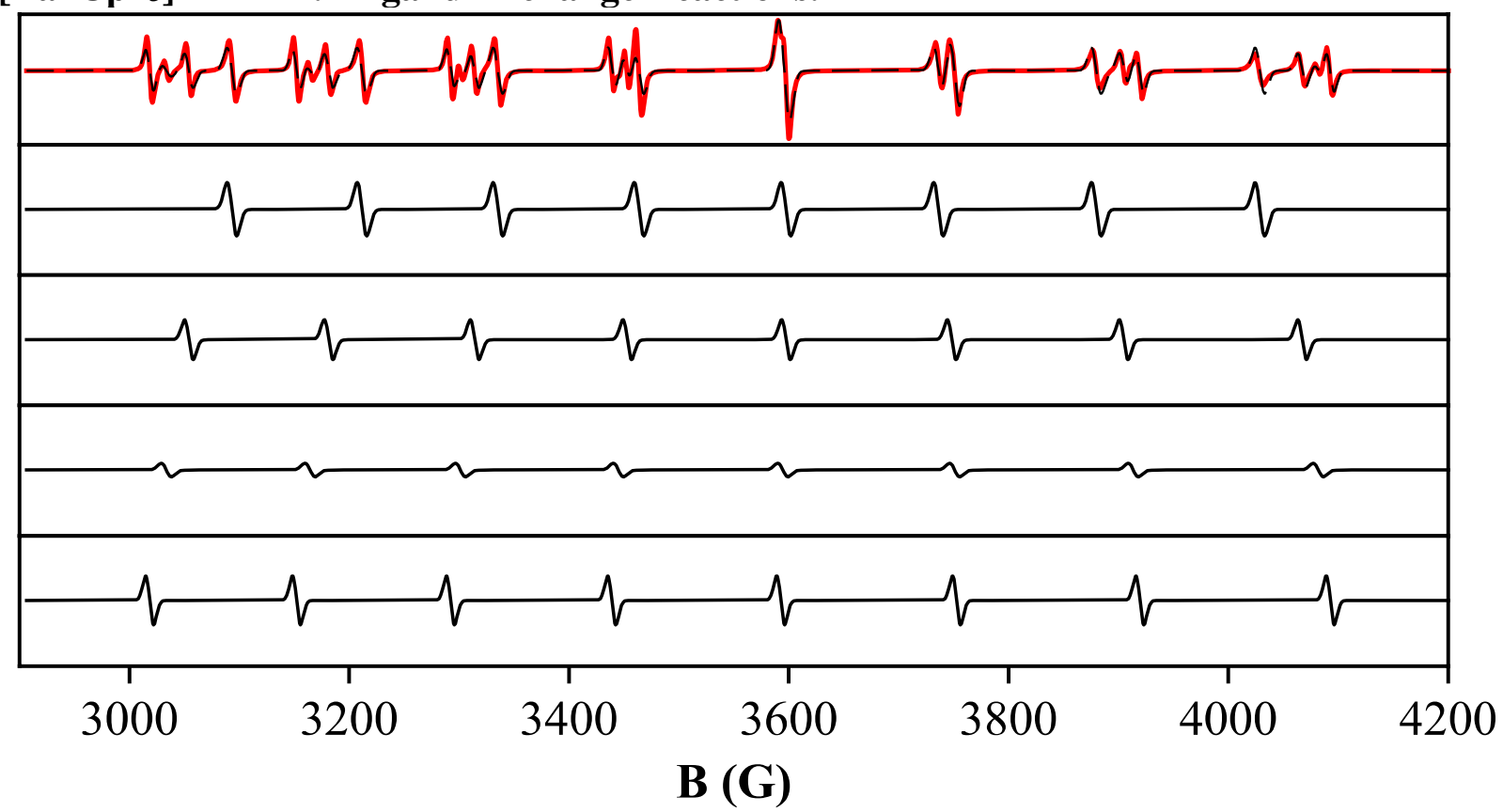

Figure S37. Room-temperature X-band EPR spectrum (red, first panel), sum of simulated signals (black dashes, first panel), and individual simulated signals (black) of the products of reaction 26. Signals are present at $g=1.97, A\left({ }^{139} \mathrm{La}\right)=133.6 \mathrm{G}\left(\left[\mathrm{La}^{\mathrm{II}} \mathrm{Cp}^{\prime \prime}{ }_{3}\right]^{1-}\right.$, second panel $), g_{C}=1.97, A_{C}\left({ }^{139} \mathrm{La}\right)$ $=144.6 \mathrm{G}(\mathbf{L a}-\mathbf{C}$, third panel $)$ and $g_{D}=1.97, A_{D}\left({ }^{139} \mathrm{La}\right)=149.7 \mathrm{G}(\mathbf{L a}-\mathrm{D}$, fourth panel $)$, and $g=$ $1.97, A\left({ }^{139} \mathrm{La}\right)=153.4 \mathrm{G}\left(\left[\mathrm{La}^{\mathrm{II}} \mathrm{Cp}^{\prime} 3\right]^{1-}\right.$, fifth panel $)$.

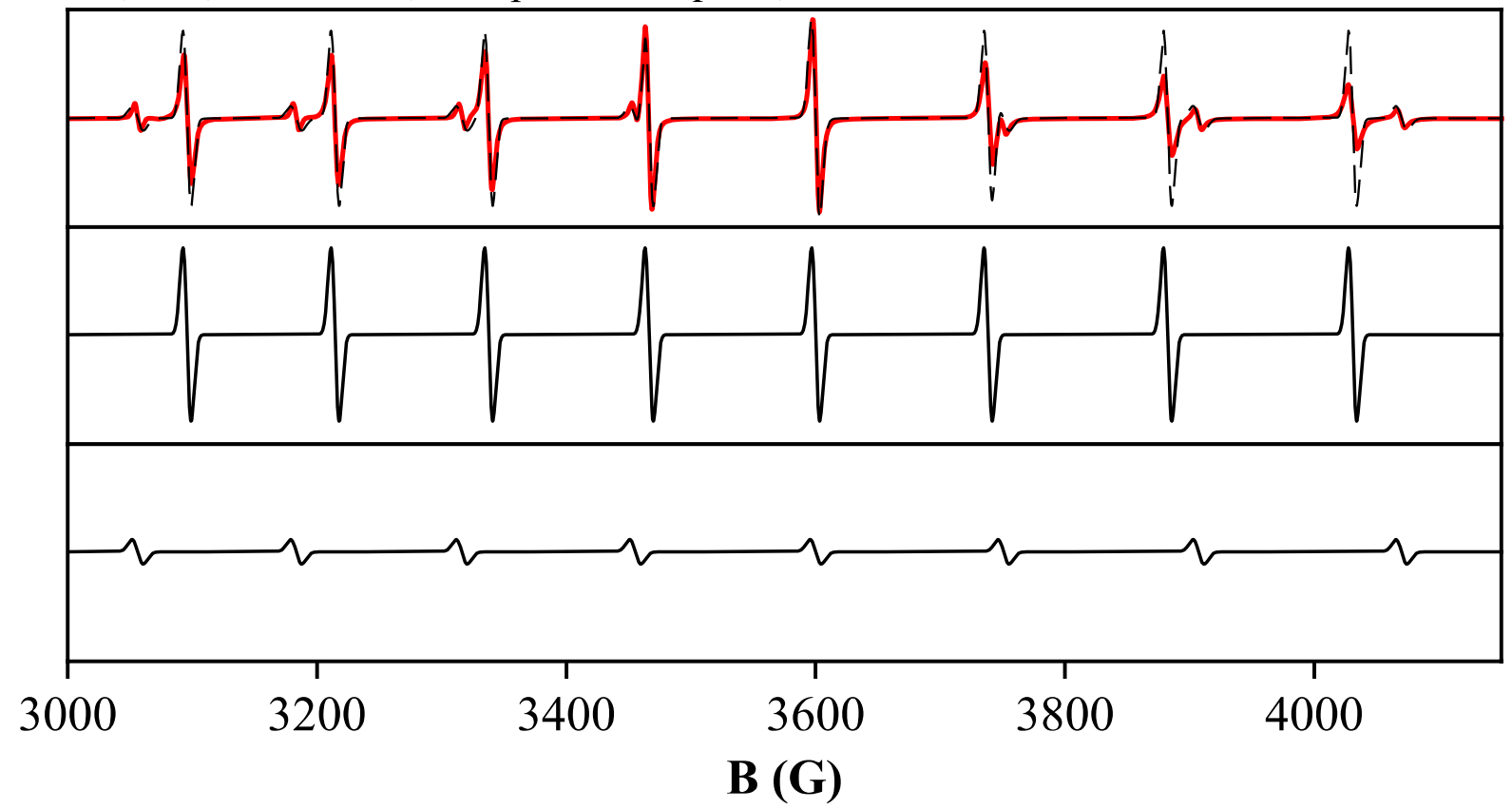

Figure S38. Room-temperature X-band EPR spectrum (red, first panel), sum of simulated signals (black dashes, first panel), and individual simulated signals (black) of the products of reaction 27. Signals are present at $g=1.97, A\left({ }^{139} \mathrm{La}\right)=133.6 \mathrm{G}\left(\left[\mathrm{La}^{\mathrm{II}} \mathrm{Cp}^{\prime \prime}{ }_{3}\right]^{1-}\right.$, second panel $)$ and $g=1.96$, $A\left({ }^{139} \mathrm{La}\right)=144.8 \mathrm{G}$ (an unknown $\mathrm{La}(\mathrm{II})$ species, third panel) . 


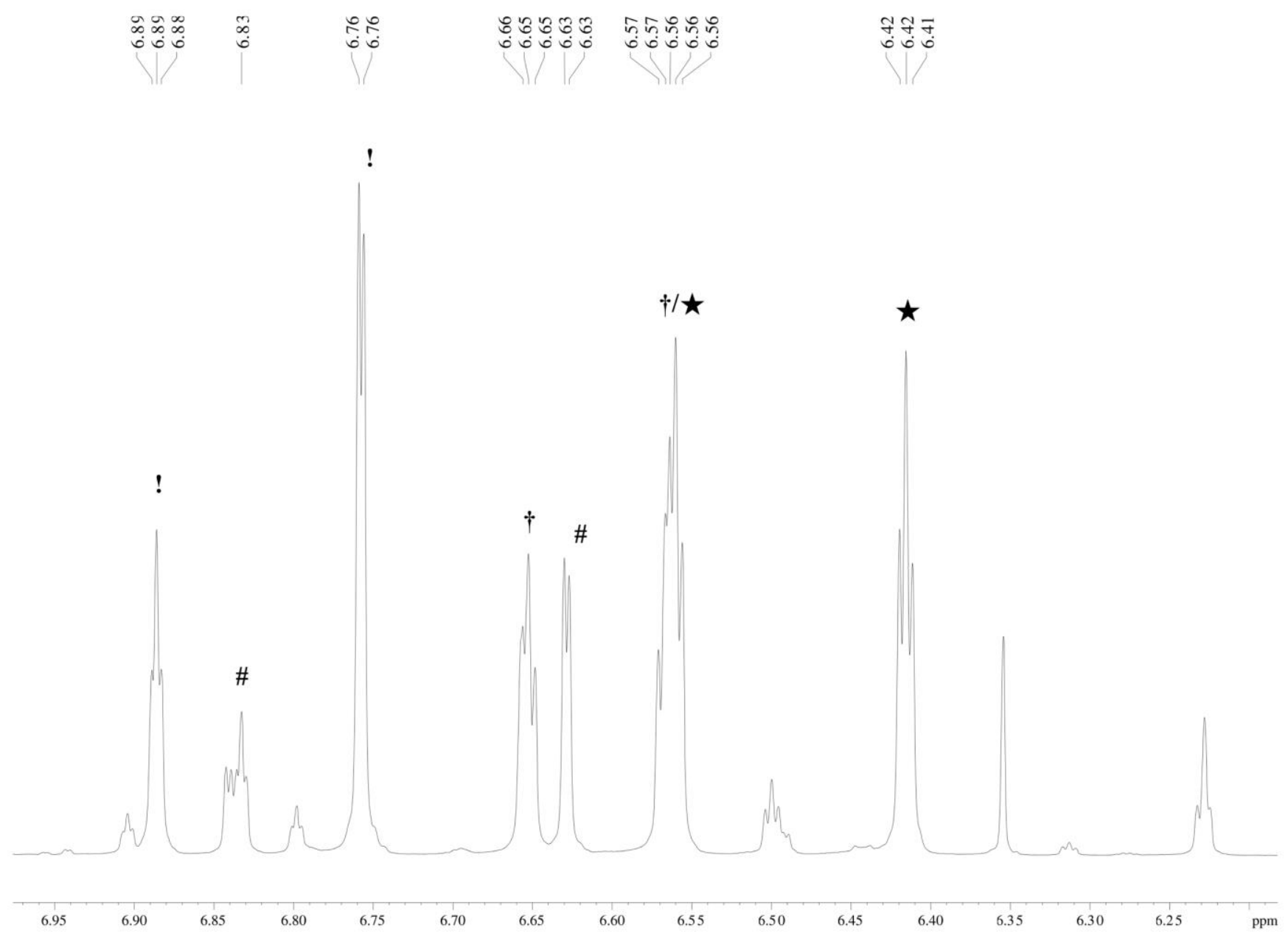

Figure S39. ${ }^{1} \mathrm{H}$ NMR spectrum of an equimolar mixture of $\mathrm{La}^{\mathrm{III}} \mathrm{Cp}^{\prime \prime}{ }_{3}$ with $\mathrm{La}^{\mathrm{III}} \mathrm{Cp}_{3}{ }_{3}(\mathrm{THF})$ in $\mathrm{C}_{6} \mathrm{D}_{6}$. ! =new $\mathrm{Cp}^{\prime \prime}$ resonance, \# = new $\mathrm{Cp}^{\prime}$ resonance, $\dagger=$ new $\mathrm{Cp}^{\prime}$ resonance, $\star=$ new $\mathrm{Cp}^{\prime}$ resonance. Multiplet at $\sim 6.56 \mathrm{ppm}$ is two overlapping $\mathrm{Cp}^{\prime}$ signals. 

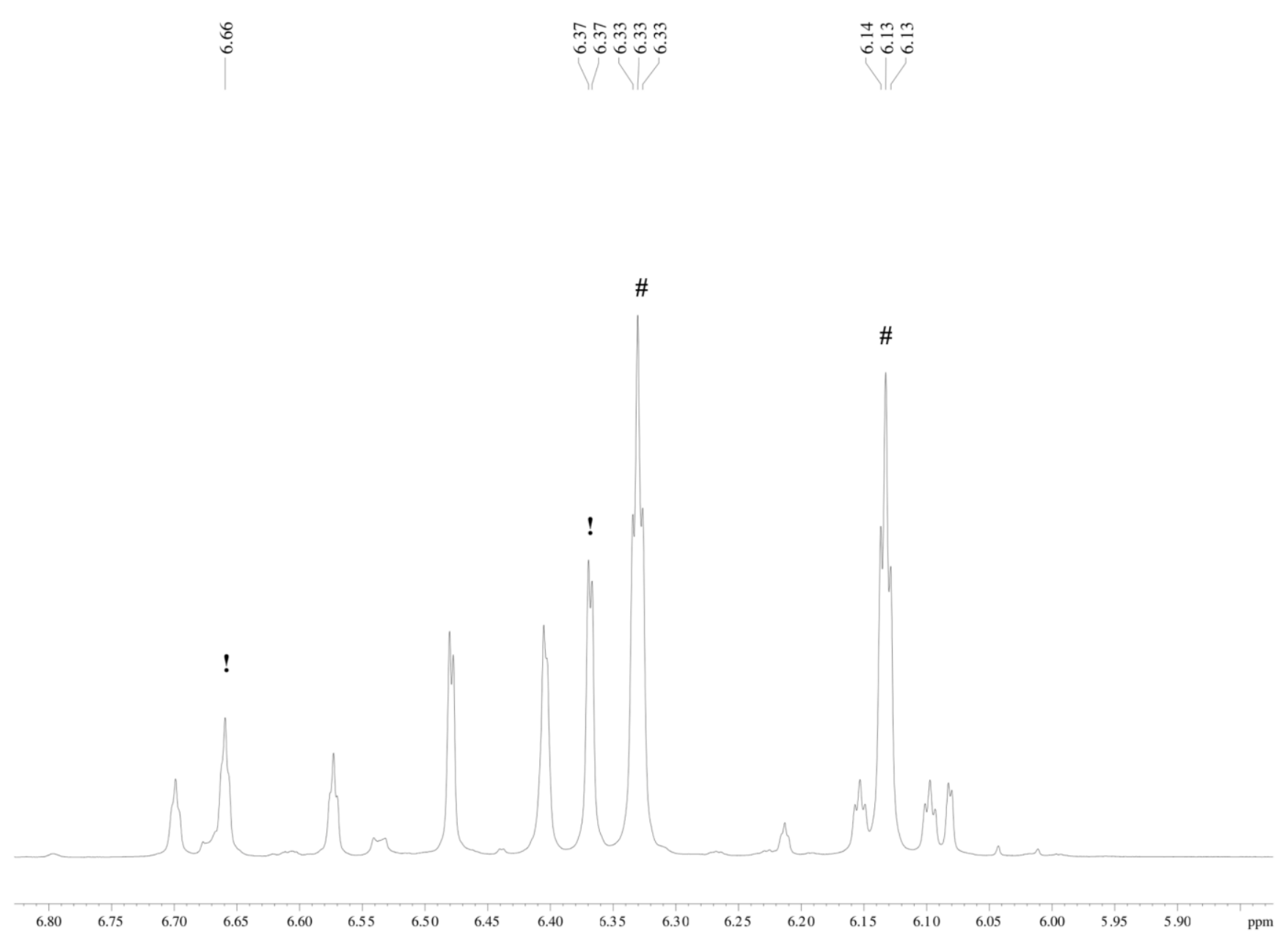

Figure S40. ${ }^{1} \mathrm{H}$ NMR spectrum of an equimolar mixture of $\mathrm{La}^{\mathrm{III}} \mathrm{Cp}^{\prime \prime}{ }_{3}$ with $\mathrm{La}^{\mathrm{III}} \mathrm{Cp}_{3}{ }_{3}(\mathrm{THF})$ in $\mathrm{THF}-d 8 . \quad !=$ new $\mathrm{Cp} "$ resonance, \# $=$ new $\mathrm{Cp}^{\prime}$ resonance. 


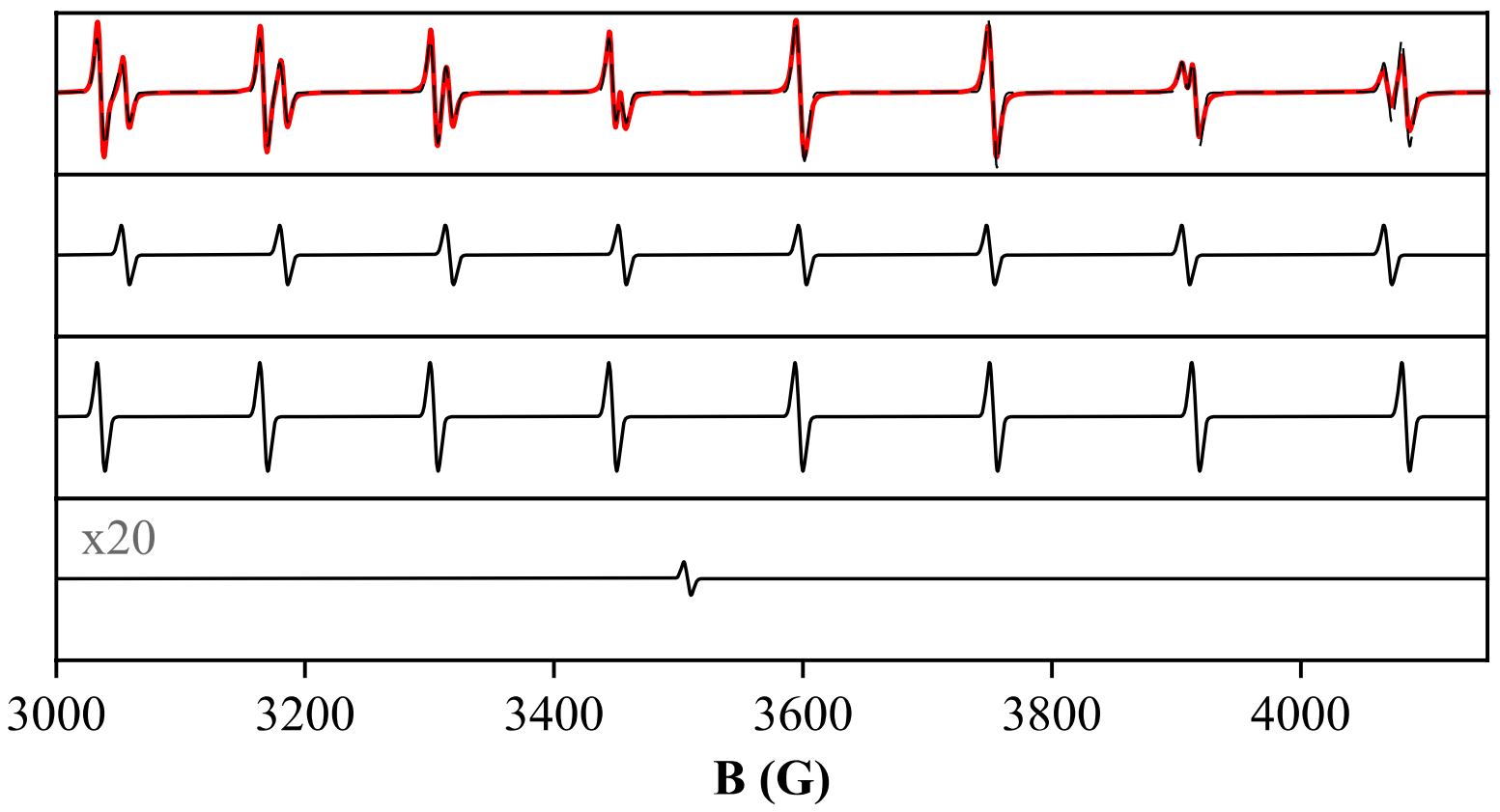

Figure S41. Room-temperature X-band EPR spectrum (red, first panel), sum of simulated signals (black dashes, first panel), and individual simulated signals (black) of the products of the reduction of a 1:1 equimolar mixture of $\mathrm{La}^{\mathrm{III}} \mathrm{Cp}^{\prime \prime}{ }_{3}$ with $\mathrm{La}^{\mathrm{III}} \mathrm{Cp}_{3}{ }_{3}$ (THF) and 1 equiv of crypt in THF- $d_{8}$. Signals are present at $g_{C}=1.96, A_{C}\left({ }^{139} \mathrm{La}\right)=144.9 \mathrm{G}(\mathbf{L a - C}$, second panel $), g_{D}=1.97, A_{D}\left({ }^{139} \mathrm{La}\right)$ $=149.7 \mathrm{G}$ (La-D, third panel), and $g=2.00$ (an unknown species, likely electride, fourth panel, magnified 20x). 


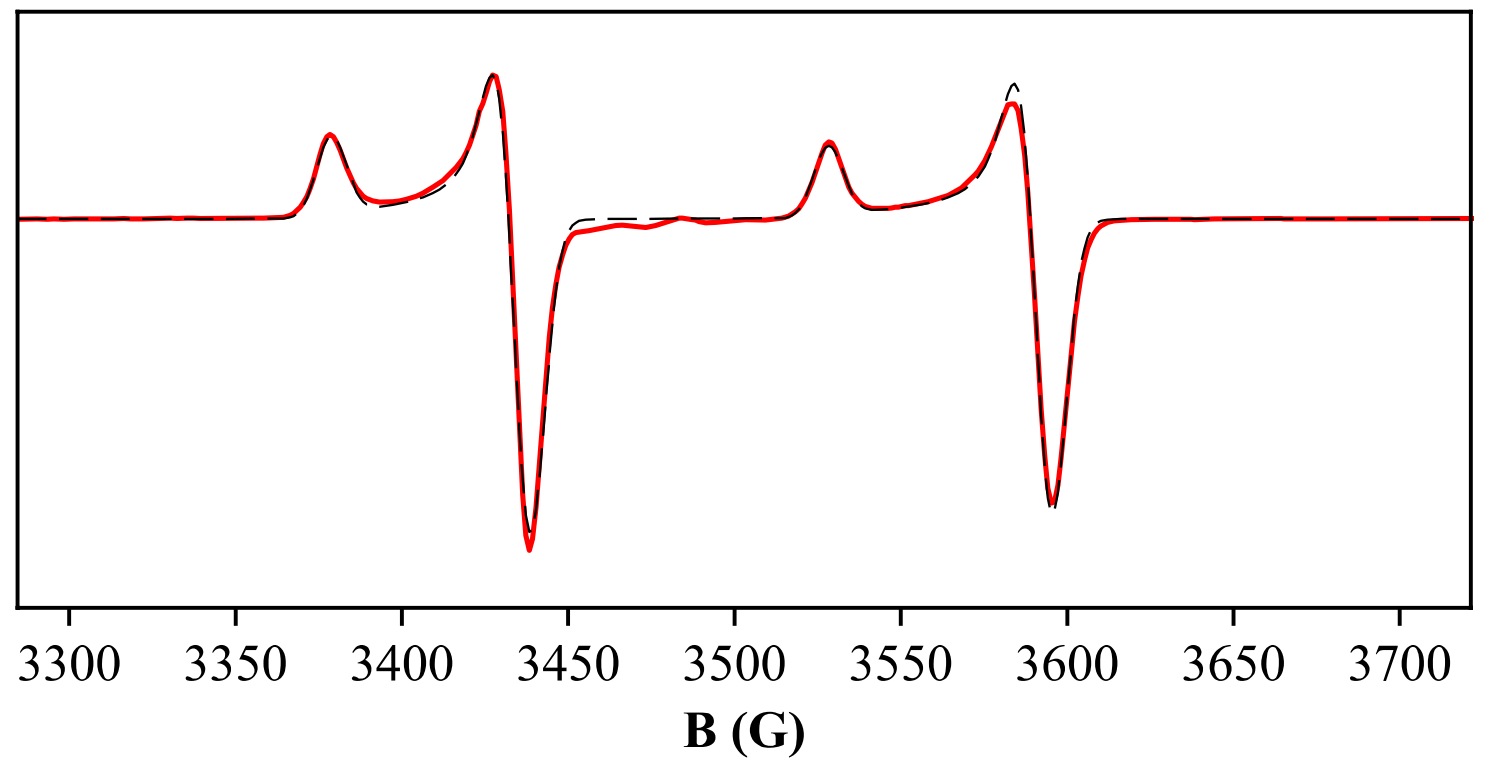

Figure S42. $77 \mathrm{~K} \mathrm{X}$-band EPR spectrum of the dark-blue species from adding a solution of crypt, reduced with $\mathrm{KC}_{8}$, to $\mathrm{Y}\left(2,6{ }^{-}{ }^{t} \mathrm{Bu}_{2}-4-\mathrm{Me}_{-} \mathrm{C}_{6} \mathrm{H}_{2} \mathrm{O}\right)_{3}$. Signal is present at $\left.g_{\perp}=1.96, g_{\|}=1.99, A_{\perp}{ }^{89} \mathrm{Y}\right)$ $=156.8 \mathrm{G}$, and $\left.A_{\|}{ }^{89} \mathrm{Y}\right)=149.4 \mathrm{G}$, consistent with a $\mathrm{Y}(\mathrm{II})$ aryloxide species. Experimental spectrum in red, simulated spectrum in black dashes. 


\section{REFERENCES}

(1) Hitchcock, P. B.; Lappert, M. F.; Maron, L.; Protchenko, A. V. Lanthanum Does Form Stable Molecular Compounds in the +2 Oxidation State. Angew. Chem. Int. Ed. 2008, 47, 1488-1491.

(2) Stoll, S.; Schweiger, A. EasySpin, a comprehensive software package for spectral simulation and analysis in EPR. J. Magn. Reson. 2006, 178, 42-55.

(3) MacDonald, M. R.; Bates, J. E.; Ziller, J. W.; Furche, F.; Evans, W. J. Completing the Series of +2 Ions for the Lanthanide Elements: Synthesis of Molecular Complexes of $\operatorname{Pr}^{2+}, \mathrm{Gd}^{2+}$, $\mathrm{Tb}^{2+}$, and $\mathrm{Lu}^{2+}$. J. Am. Chem. Soc. 2013, 135, 9857-9868. 